San Jose State University

SJSU ScholarWorks

Master's Theses

Master's Theses and Graduate Research

2006

\title{
Changes in body weight, RMR, and body composition in college freshman students
}

Danielle Lauren Cook

San Jose State University

Follow this and additional works at: https://scholarworks.sjsu.edu/etd_theses

\section{Recommended Citation}

Cook, Danielle Lauren, "Changes in body weight, RMR, and body composition in college freshman students" (2006). Master's Theses. 2874.

DOI: https://doi.org/10.31979/etd.fn88-2cdx

https://scholarworks.sjsu.edu/etd_theses/2874

This Thesis is brought to you for free and open access by the Master's Theses and Graduate Research at SJSU ScholarWorks. It has been accepted for inclusion in Master's Theses by an authorized administrator of SJSU ScholarWorks. For more information, please contact scholarworks@sjsu.edu. 


\title{
CHANGES IN BODY WEIGHT, RMR, AND BODY COMPOSITION IN COLLEGE FRESHMEN STUDENTS
}

\author{
A Thesis \\ Presented to \\ The Faculty of the Department of Nutrition and Food Science \\ San Jose State University
}

\author{
In Partial Fulfillment \\ Of the Requirements for the Degree \\ Masters of Science
}

By

Danielle Lauren Cook

May 2006 
UMI Number: 1436900

\section{INFORMATION TO USERS}

The quality of this reproduction is dependent upon the quality of the copy submitted. Broken or indistinct print, colored or poor quality illustrations and photographs, print bleed-through, substandard margins, and improper alignment can adversely affect reproduction.

In the unlikely event that the author did not send a complete manuscript and there are missing pages, these will be noted. Also, if unauthorized copyright material had to be removed, a note will indicate the deletion.

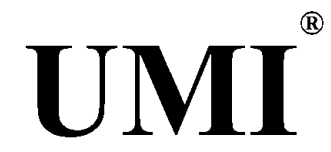

UMI Microform 1436900

Copyright 2006 by ProQuest Information and Learning Company.

All rights reserved. This microform edition is protected against unauthorized copying under Title 17, United States Code.

ProQuest Information and Learning Company

300 North Zeeb Road

P.O. Box 1346

Ann Arbor, MI 48106-1346 
(C) 2006

Danielle Lauren Cook

ALL RIGHTS RESERVED 


\section{APPROVED FOR THE DEPARTMENT OF \\ NUTRITION AND FOOD SCIENCE}

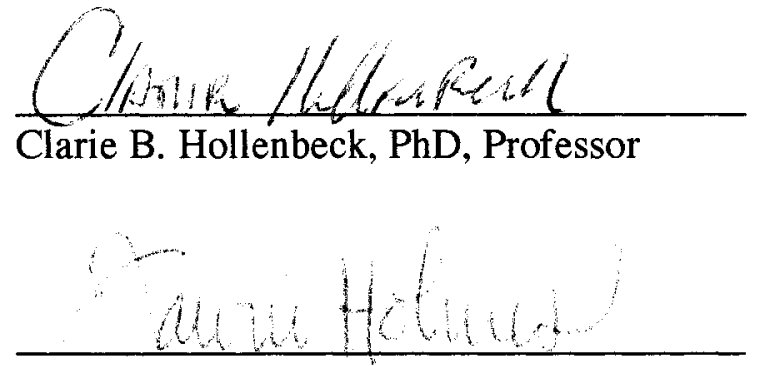

Tawni Holmes, $\mathrm{PhD}, \mathrm{RD} / \mathrm{LD}$ Assistant

Professor, University of Central Oklahoma, Edmond OK

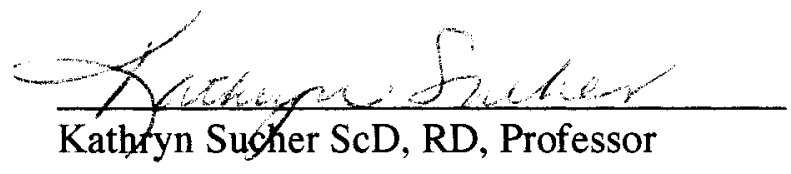

APPROVED FOR THE UNIVERSITY

When \% Wuhamean 03/25/06 


\title{
ABSTRACT \\ CHANGES IN BODY WEIGHT, RMR, AND BODY COMPOSITION IN COLLEGE FRESHMEN STUDENTS
}

\author{
by Danielle L. Cook
}

The purpose of the present thesis was to investigate changes that occurred in body weight, body composition and RMR, the influence of lifestyle, and whether or not weight gain is long-lasting or transient in college freshmen. In addition, four commonly used methods of estimating RMR were compared. The present study demonstrates that a significant amount of weight is gained upon entering the first year of college. Overall, weight gain appeared to be variable and transient in nature. The data in this study demonstrates that weight gain in some individuals can be substantial; however, a small amount of exercise may be protective against initial weight gain in this population.

Measurements of RMR by BIA and $\mathrm{O}_{2}$, as well as calculated estimates of RMR by metabolic body size, Harris-Benedict, and Mifflin/St.Jeor equations were compared. Results from the present study indicate that all five methods provide reasonably similar estimates. 


\section{ACKNOWLEDGEMENTS}

This research would not have been possible without the ongoing encouragement and guidance from my academic committee: Clarie Hollenbeck, PhD; Tawni Holmes, $\mathrm{PhD}, \mathrm{RD} / \mathrm{LD}$; and Kathryn Sucher, DSc, RD. Dr. Hollenbeck, thank you for your never ending support, confidence in my abilities, and sharing your vast knowledge of nutrition with me. Dr. Holmes, thank you for gaining funding for this research and providing thoughtful insight on the direction and details of this thesis. Dr. Sucher, thank you for your important comments concerning the presentation and write-up of this thesis.

I also thank my best friend, Joel, and my parents for their love and support throughout my academic career at San Jose State University. 


\section{PREFACE}

Journal article one contained in Chapter 2 was prepared according to the publication guidelines for The Journal of the American Dietetic Association. Journal article two contained in Chapter 2 was prepared according to the publication guidelines of The New England Journal of Medicine. The remainder of the thesis is written according to the Publication Manual of the American Psychological Association ( $6^{\text {th }}$ edition, 2002). 


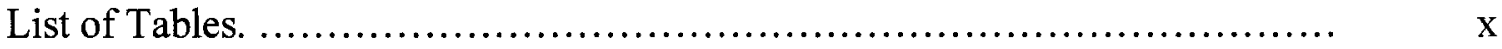

List of Figures.....................................................

CHAPTER 1 Introduction and Review of Literature ........................ 1

Introduction.................................................. 2

Review of Literature........................................... 3

Overweight and Obesity................................. 3

Characteristics of Weight Gain............................ 5

Energy Balance....................................... 7

Weight Gain in College Freshmen........................... 13

Lifestyle Practices of Freshmen Students................... 14

Previous Studies Showing Freshman Weight Gain.............. 15

Summary and Conclusions............................... 16

CHAPTER 2 Journal Articles.......................................... 18

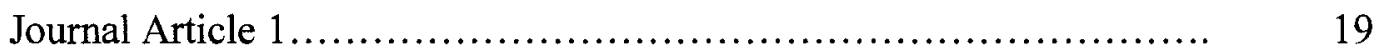

Author's Title Page.............................................. 20

Abstract.......................................................... 21

Introduction.................................................... 23

Methods and Procedures........................................... 24

Results...................................................... 27

Discussion................................................. 27 
Acknowledgements............................................. $\quad 30$

References.................................................... 31

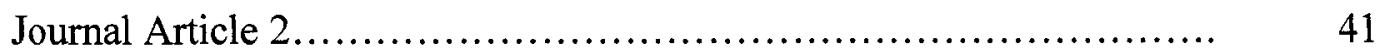

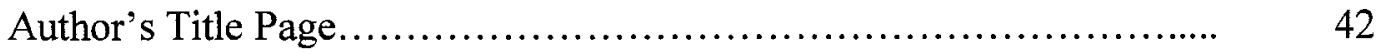

Abstract....................................................... 43

Introduction.................................................. $\quad 45$

Methods and Procedures........................................ 46

Results.......................................................... $\quad 50$

Discussion..................................................... 54

Conclusions........................................................ 57

Acknowledgements............................................ 59

References..................................................... 60

CHAPTER 3 Summary and Recommendations............................. 72

Summary and Recommendations.................................. 73

References.................................................... $\quad 75$

Appendixes...................................................... 81

Appendix A IRB Approval................................... 82

Appendix B Consent Form................................... $\quad 83$

Appendix C Exercise Surveys............................... $\quad 85$ 


\section{List of Tables}

Tables

Journal Article 1

1. Clinical and Demographic Characteristics of 62 Young Healthy Men and Women Undergoing Testing for Resting Metabolic Rates...................

2. Estimated Resting Metabolic Rate for Ventilated Oxygen Consumption $\left(\mathrm{O}_{2}\right)$, Bioelectrical Impedance (BIA), Metabolic Body Size $\left(\mathrm{Kg}^{0.75}\right)$, HarrisBenedict (HB-BEE), and Mifflin / St. Jeor (MSJ) Equations

3. Correlation Coefficients Between Ventilated Oxygen Consumption $\left(\mathrm{O}_{2}\right)$, Bioelectrical Impedance (BIA), Metabolic Body Size $\left(\mathrm{Kg}^{0.75}\right)$, HarrisBenedict (HB-BEE), and Mifflin / St. Jeor (MSJ) Equations

Journal Article 2

1. Clinical Characteristics of the 63 Study Subjects Studied for 16 Weeks and the Sub-Group of 29 Followed for 1 Year.................................

2. Changes in Body Weight, Body Composition, RMR, Total Energy Intake, and Macronutrient Composition in Diets of 63 College Freshmen............

3. Correlation Coefficients between Changes in Body Weight, Body Composition, RMR, and Total Energy Intake of College Freshmen Participants During the 16 - Week Study Period............................

4. Exercise Patterns Among 36 First Semester Freshmen Students..............

5. Changes in Weight, Fat Mass, and RMR in College Freshmen Who Followed the American College of Sports Medicine (ACSM) Recommendations for Exercise and Those Who Did Not.

6. Changes in Body Weight in 29 Freshmen Students at $16-W e e k s$, and at 1 Year Follow-up 
List of Figures

Figure $\quad$ Page

Journal Article 1

Correlations Between Ventilated Oxygen Consumption $\left(\mathrm{O}_{2}\right)$, Bioelectrical Impedance (BIA), Metabolic Body Size $\left(\mathrm{Kg}^{0.75}\right)$, Harris-Benedict (HB-BEE), and Mifflin / St. Jeor (MSJ) Equations RMR................................

Journal Article 2

1. Individual Changes in Body Weight in 63 First Semester Freshmen..........

2. Changes in Body Weight in 29 Freshmen Students at 16 Weeks (a), between 16 Weeks and 1 Year (b), and at the End of 1 Year (c)....................... 
CHAPTER 1

INTRODUCTION AND REVIEW OF LITERATURE 
Introduction

Overweight and obesity has increased dramatically in the United States in the past 30 years. According to the 1999-2000 National Health Nutrition Examination Survey (NHANES IV) an estimated $64 \%$ of adults and $15 \%$ of children and adolescents ages 619 years old in the United States are either overweight or obese (Center for Disease Control (CDC), 2004).

Obesity is a serious health risk, which has created considerable concern among clinicians and health care providers. Approximately 300,000 annual deaths are attributed to obesity (Allison, Fontaine, Manson, Stevens, \& VanItallie, 1999). Studies have linked excess weight to an increased risk of chronic health conditions such as cardiovascular disease, hypertension, and type 2 diabetes (US Department of Health and Human Services, 1996; Stein and Colditz, 2004; Bray, 2004).

Weight loss of as little as $10 \%$ of a person's initial body weight, or $5 \mathrm{~kg}$, has been shown to greatly decrease a person's risk of developing weight related diseases (Eckel and Krauss, 1998; Colditz, Willett, Rotnitzky, Manson, 1995; Huang et al., 1998). Although weight loss is often achieved, maintaining weight loss is far less common (Davey, 2004). Because current weight loss programs have little long-term success, identifying the causes of weight gain and developing prevention strategies is critical in weight control (Matvienko, Lewis, Schafer, 2001).

Research has shown that weight gain begins early in life (US Department of Health and Human Services, 1996). There are several periods throughout life when weight gain is common and the freshmen year of college appears to be a particularly 
important one. There is a well-known belief that freshmen gain approximately 15 pounds during their first year of college. This notion is commonly referred to as "The Freshman 15". Previous studies that investigated freshman weight gain found that the average weight gain was far less than 15 pounds and may be closer to approximately 5 pounds; however, weight gain was highly variable between individuals (Graham and Jones, 2002; Hodge et al., 1993; Hojhosseini et al., 2003; Levitsky, Halbmaier, \& Mrdjenovic, 2004). Because the first year of college appears to be a time when accelerated weight gain occurs, studying freshman weight gain may not only aid in developing prevention strategies for weight gain in this population, but it may also enhance our understanding of weight gain in the general population. The purpose of the present study is to add to the existing literature on college freshman weight gain, assess how this weight is gained, investigate if changes in RMR occur, how specific dietary and exercise practices influence weight gain in college freshmen, and whether or not this weight gain is transient or long lasting.

\section{Review of Literature}

\section{Overweight and Obesity}

Definition The CDC defines obesity as having an extremely high amount of body fat in relation to lean body mass, or having a Body Mass Index (BMI) of 30 or higher (CDC, 2004). High body fat (over $25 \%$ in men and $32 \%$ in women) and a BMI of over 25 are highly correlated with the development of weight related diseases (CDC, 2004). BMI is calculated by dividing a person's weight in $\mathrm{kg}$ by a person's height in meters squared $\left(\mathrm{kg} / \mathrm{m}^{2}\right)$. BMI is an accurate tool for classifying overweight and obesity in the 
majority of the population; however, it does have limitations. For example, an athlete who is very lean and muscular may weigh more than someone who is the same height, but sedentary. Using BMI to assess their weight may qualify them as overweight, although they clearly are not over fat. Thus, using BMI to assess a healthy weight fails to accurately distinguish a person's body composition. In an ideal setting, both BMI and body composition measurements should be employed to more accurately assess healthy body weight.

Prevalence and Trends According to the 1999-2000 NHANES IV an estimated $64.5 \%$ of adults are overweight (BMI $\geq 25$ ) and $30.5 \%$ of adults are obese (BMI $\geq 30$ ) in the United States (CDC, 2004). This is an $8 \%$ increase from the age-adjusted overweight estimates gathered from NHANES III (1988-1994). Obesity trends are not only increasing in adults, but also in children. Results from the 1999-2000 NHANES indicate that approximately $15 \%$ of children and adolescents ages 6-19 years old are overweight. This is a 4\% increase from the overweight estimates of the NHANES III (1988-1994) (CDC, 2004). These data suggest that overweight and obesity is beginning at a younger age. This notion is supported by a prospective cohort study, which observed that men and women born in 1964 became obese at a younger age than men and women who were born in 1957. In addition, $>25 \%$ of the participants born in 1964 were obese by their mid-30s (McTigue et al., 2002).

Obesity and Chronic Disease Obesity is of great concern to clinicians and health experts. It is not only psychologically damaging, but it is also a great threat to one's health. Approximately 300,000 annual deaths are attributed to obesity (Allison et al., 
1999). A large study performed in the United States found that a high BMI is associated with higher rates of death among both men and women in all age groups (Calle, Thun, Petrelli, Rodriguez, \& Heath, 1999). Several studies have linked excess weight to an increased risk of weight related health conditions, including cardiovascular disease, insulin resistance, metabolic syndrome, nonalcoholic fatty liver disease and nonalcoholic steatohepatitis, type 2 diabetes, cancer, premature death, hypertension, cerebrovascular disease, gallstones, osteoarthritis, sleep apnea, asthma, dyslipidemia, menstrual irregularities, pregnancy complications, endocrine changes, depression, and social discrimination (US Department of Health and Human Services, 1996; Stein and Colditz, 2004; Bray, 2004).

\section{Characteristics of Weight Gain}

Difficulty of Weight Loss and the Importance of Prevention Solving the obesity epidemic has become a major focus in the United States and throughout the world. This has led to the development of several weight loss programs and diets. It has been estimated that approximately $75 \%$ of women and $47 \%$ of men have attempted weight loss at some time in their life (Jeffery et al., 2000). Successful weight loss can often be achieved; however, weight maintenance is much more difficult. Increasing trends of overweight and obesity suggest that long-term weight loss may be unsuccessful (Jeffery et al., 2000). A meta-analysis of 29 studies, which examined the success of maintaining weight loss after 5 years, found that individuals who lost weight were only able to maintain a $3 \mathrm{~kg}$ weight loss below their initial weights (Davey, 2004). It has been estimated that 90 to $95 \%$ of persons who lose weight regain their weight (Rosenbaum et 
al., 1997). Studies have shown that weight gained is rarely reversed and chronic weight cycling can make weight loss harder and slower each time weight is gained (Blackburn et al., 1989). McTigue et al., 2002 observed that $>80 \%$ of participants who were obese at age 20 to 22 years were still obese at age 35 to 37 years. Because current weight loss programs have little long-term success and weight is rarely reversed, prevention of weight gain is critical in weight control.

Time in Life Span Targeting when weight is gained throughout the lifespan and who is at the greatest risk for becoming obese are important factors in slowing the rate of obesity in the United States. Weight gain often begins between 18 and 34 years of age; however, overweight and obesity is developing at an earlier and earlier age (Matvienko et al., 2001). The average yearly weight gain observed in adulthood is 0.2 to $0.8 \mathrm{~kg}(0.44$ to $1.76 \mathrm{lbs}$.) and an average of $9.1 \mathrm{~kg}(20 \mathrm{lb}$.) is gained between the ages of 25 and 55 years (Matvienko et al., 2001; Rosenbaum et al., 1997). There are several periods throughout life when weight gain is common, such as, adolescence, pregnancy, midlife in women and the period after marriage in men (Yanovski et al., 2000). As people grow older they typically gain weight. Cross-sectional studies have demonstrated that a $1 \%-2 \%$ decrease in resting metabolic rate (RMR) occurs approximately every decade as a person ages, beginning somewhere in their mid-twenties (Gilliat-Wimberly, Manore, Woolf, Swan, Carrol, 2001). These changes occur primarily as a result of decreasing physical activity, which leads to a loss of muscle and a lower 24-hour energy expenditure. The first year of college also appears to be a time when an accelerated amount of weight is gained. This period of weight gain will be discussed in greater detail later in the paper. 
Factors Leading to Weight Gain There is constant debate among health care providers and researchers as to why weight is gained. Understanding why weight is gained is critical to slowing or halting the increase in obesity that has been observed over the last 30 years. Overweight and obesity are the result of a culmination of factors, which include genetic, metabolic, behavioral, and environmental influences (Stein and Colditz, 2004). All of these factors impact body weight; however, the prevalence of overweight has increased by $40 \%$ and the prevalence of obesity has grown $110 \%$ in the last 25 years (CDC, 2004). This sudden increase in obesity suggests that behavioral and environmental influences, not genetics, have had the greatest influence on weight gain in the United States. Leading experts contribute weight gain to an energy imbalance (CDC, 2004). The first law of thermodynamics states that the amount of stored energy (stored as fat) is equal to the difference between energy intake and energy expenditure (Rosenbaum et. al, 1997). An important question exists: How has energy balance shifted towards a positive balance? Although there is no clear explanation, it is evident that in the United States food options, portion sizes, and the amount of convenience foods have increased, while the growing use of technology has greatly diminished energy expenditure. When calorie consumption exceeds calorie expenditure, the result is a positive energy balance and weight gain. We will examine each side of the energy equation in more detail.

\section{Energy Balance}

Diet The 1999-2000 Healthy Eating Index concluded that only $10 \%$ of Americans ate a "good diet," $16 \%$ ate a "poor diet," and $74 \%$ "needs improvement" (Putnam, Allshouse, Kantor, 2002). This data suggests poor eating habits. It only 
requires a small amount of extra energy daily to result in weight gain. For example, a positive energy balance of 9 kcals daily (such as a stick of sugar free gum) will result in approximately 1 pound of weight gained yearly. As pointed out previously, the average yearly weight gain in American adults is approximately 1 pound (Matvienko et al., 2001). Our society has created an environment where food is inexpensive, highly palatable and easily accessible, which has made eating a convenience rather than a necessity. Portion sizes have increased substantially. For example, Coca Cola individual serving bottles have increased from 6.5 ounces to 20 or 32 ounces (Davey, 2004). Data from NHANES I, NHANES II and NHANES III, which analyzed diets in the United States from 19712000 , indicate an increase in mean energy intake (kcals) (CDC, 2004). The average reported increase in daily energy intake for men was from 2,450 kcals to 2,618 kcals. In women it increased from $1,542 \mathrm{kcals}$ to $1,877 \mathrm{kcals}$ (CDC, 2004). Diet composition and location where foods were consumed also changed. Between 1977 and 1996 the number of meals consumed at restaurants and fast-food establishments compared to meals eaten at home increased from $9.6 \%$ to $23.5 \%$, and the greatest increase was observed in people ages 19-39 years (Nielson, Siega-Riz, Popkin, 2002). Changes in dietary composition included an increase in percentage of carbohydrate and a decrease in percentage of fat consumed. Despite popular belief, research has shown that dietary composition has little to do with the development of obesity (Rosenbaum et al., 1997; Roust, Hammel, Jensen, 1994; Golay et al., 1996). Consumption of sugared beverages, French-fries, hamburgers, cheeseburgers, pizza, and Mexican food, which could potentially increase energy intake 
has increased (Nielson et al., 2002). Unlike macronutrient composition, these trends in food choices suggest a general increase in energy intake.

Total Energy Expenditure Dietary intake plays a large role in energy balance; however, experts suggest that the recent increase in obesity is mainly due to a decrease in energy expenditure (Mayo Clinic, 2002; Pescatello and VanHeest, 2000). Total daily energy expenditure (TEE) is dependent on the following three variables: Resting metabolic rate (RMR), thermic effect of food (TEF) and physical activity (Matvienko et al., 2001). TEF accounts for approximately $10-15 \%$ of 24 -hour energy expenditure (EE) and varies depending on diet (Mifflin et al., 1990). Physical activity is also highly variable between individuals and may contribute between $20-30 \%$ of TEE. Because TEF and physical activity between individuals is so variable from day to day, RMR is most frequently used as a predictor of 24-hour EE. RMR accounts for approximately $65-70 \%$ of TEE, and is best predicted by lean body mass (LBM) (Mifflin et al., 1990; Foster et al., 1988; Owen et al., 1987; Brooks, Fahey, White, Baldwin (2000).

There is no clear definition or consistent protocol for measuring RMR. Nieman, Trone and Austin (2003) defined RMR in their study as metabolic measurements taken at least 4 hours postprandial and a minimum of 4 hours post exercise, with subjects in a seated position after ten minutes of rest in the late afternoon. Case, Brahler and Heiss (1997) defined RMR as the amount of energy used by the body in a rested (no exercise for a minimum of 24 hours), fasted state (12 hours postprandial) at a thermoneutral temperature $\left(21-22^{\circ} \mathrm{C}\right)$. Brooks et al. $(2000)$ defined RMR as the energy required in a fully conscious person at rest and 8-12 hours after exercise or a meal (Brooks, et al., 
2000). Although no consistent protocol has been determined, Owen et al. (1986) determined that the coefficient of variation for measuring 8 fasted subjects at 20 different times over an 8 hour period was $\pm 4.7 \%$. This data suggests that as long as subjects are fasting, have not exercised, and are resting quietly while measured, the time of day when RMR is measured will result in only slight variations in estimating RMR.

Measuring RMR The "Gold Standard" for determining resting metabolic rate (RMR) is direct calorimetry. However, this procedure is expensive and requires specialized facilities for proper determination. As a result, indirect methods that allow reasonably accurate estimates of RMR have been developed. Several indirect methods for measuring and predicting RMR exist. Two widely used methods for estimating RMR are the measurement of ventilated oxygen consumption $\left(0_{2}\right)$ and estimates of lean body mass and body cell mass using bioelectrical impedance (BIA). All energy-releasing reactions in the body depend on biological oxidation; therefore, measuring oxygen consumption provides a reliable estimate of energy expenditure.

Measuring Lean Body Mass If LBM is used in estimating RMR it is important that accurate methods of assessing LBM are employed. Hydrodensitometry (underwater weighing) and Dual-energy x-ray absorptiometry (DEXA) are the "Gold Standard" for estimating body fat (Willett, Dietz, Colditz, 1999). Because both of these methods are expensive and require skilled technicians, they are used primarily in research settings and to validate less complicated, inexpensive methods such as body circumference (waist to hip ratio), skin-fold thickness, and bioelectrical impedance (BIA). 
BIA passes a low frequency electrical current through extremity (e.g., arm) and the impedance to the electrical flow is measured through the other extremity (e.g., leg) on the same side of the body. Measurement of BIA is based on the assumption that lean tissue is a better conductor of electricity, and therefore, will conduct current better than fat mass. Resistance is then combined with height and weight into an equation to derive an estimate of body composition. Most studies have found that BIA is equally as accurate as skin fold technique; however, it has been found to be less accurate in estimating body composition in very lean and very obese people (Brooks et al., 2000).

Physical Activity Because exercise will potentially help build muscle, it may also increase RMR (Brooks et al., 2000; Gilliat-Wimberly et al., 2001). In addition to increasing RMR, exercise is also important for expending calories. Approximately $5 \mathrm{kcal}$ are utilized for every liter of oxygen consumed during exercise (Brooks, 2000). If a person expends 300 calories per exercise session and performs this 3 or 4 times every week, they would lose 13 to 23 pounds of fat in 1 year (assuming that they are on an isocaloric diet) (Brooks, 2000). A 15-50\% elevation in energy expenditure above RMR during the recovery period from exercise, commonly referred to as excess post-exercise oxygen consumption (EPOC), has also been observed (Binzen, Swan, Manore, 2001; Brooks, 2000). Research has shown that strength training and aerobic exercise performed at the same intensity both cause a similar increase in 24-hour energy expenditure in men (Melanson et al., 2002).

Although physical activity is critical to successful weight control and good health, research shows that few Americans are physically active. According to the Behavioral 
Risk Factor Surveillance System in 2000, less than $1 / 3$ of adults performed the recommended amount of physical activity and $40 \%$ of adults in the United States are completely sedentary (National Institute of Health (NIH), 2004). Youth in the United States was also found to be inactive. Only $25 \%$ of $12-21$ year olds engage in light to moderate activity on a daily basis and only approximately $50 \%$ participate regularly in vigorous physical activity (NIH, 2004).

Recommendations for physical activity have been suggested in an attempt to increase the level of physical activity in the Untied States. The U.S. Department of Health and Human Services recommends that Americans engage in a minimum of 30 minutes (adults) or 60 minutes (children) of light or moderate physical activity 5 or more days of the week and/or vigorous activity 3 times or more per week for 20 minutes or more each time (U.S. Department of Health and Human Services, 1996). Moderate physical activity includes activities such as brisk walking or dancing. Examples of vigorous activities include running or playing basketball.

The American College of Sports Medicine (ACSM) recommends that healthy people should perform aerobic exercise 3 to 5 days a week at $40 \%$ or $50 \%$ to $85 \%$ of their maximum oxygen uptake reserve (moderate to vigorous physical activity, respectively) for 20 to 60 minutes (ACSM, 2004). Exercise can be performed in 10-minute bouts for an accumulation of 20 to 60 minutes throughout the day. ACSM also recommends that people younger than 50 years old should perform resistance training 2-3 days per week. They recommend performing one exercise of 8 to 12 repetitions for all major muscle groups (chest, back, legs, biceps, triceps, and abdominals) (ACSM, 2004). 


\section{Weight Gain in College Freshmen}

There is a well established belief that freshmen gain approximately 15 pounds during their first year of college. This notion is commonly referred to as "The Freshman 15." Although this notion is well known and feared, freshmen still continue to gain weight upon entering college (Graham and Jones, 2002; Hodge et al., 1993; Hojhosseini et al., 2003). Previous studies that investigated freshman weight gain found that the average weight gain was far less than 15 pounds (Graham and Jones, 2002; Hodge et al., 1993; Hojhosseini et al., 2003). Graham and Jones (2002) reported an average weight gain of 4.6 pounds in a small sample of college freshmen; however, it is important to note that 10 subjects gained between $5-9.5$ pounds and 3 subjects gained between $10-15 \mathrm{lbs}$. in the nine-month study. Over half of the subjects gained weight (Graham and Jones, 2002). In another study, eighteen of the 61 subjects gained 4 pounds or more in their first year of college (Hodge et al., 1993). These findings are similar to a small, 16 week study performed at a large, ethnically diverse university, which reported a weight gain of $\geq 3$ pounds in 16 of the 26 subjects (Hajhosseini et al., 2003). Hodge et al. (1993) found that the average weight gain in college women in their first 6 months of college was 7 pounds. Although the reported weight gain in these four studies was not fifteen pounds, it is important to note that there was a relatively large increase in weight. It is imperative to remember that the weight gain observed in these studies occurs within only nine months or less, and that this weight gain far exceeds the average yearly weight gain. 


\section{Lifestyle Practices of Freshmen Students}

The first year of college is an important time in a young adult's life. As a result of a newfound independence and a necessity to make dietary choices on their own, the freshman year is often a time that students begin to form life-long eating behaviors (Sax, 1997). Deciphering what to eat and how to maintain or achieve a healthy weight requires a basic understanding of nutrition and human physiology. Most freshmen students were not provided with this knowledge in high school and, therefore, have a difficult time dealing with weight gain that commonly occurs with age (Matvienko, 2001). Much of the nutrition information that students learn is derived from home economics classes, television, parents, coaches, friends, labels on food packages, radio, non-scientific books, newspapers and magazines. These sources contain simplified nutritional concepts and lack the necessary information on how biology and nutrition interact and control weight (Matvienko, 2001); therefore, most college freshmen do not have the appropriate knowledge to safely maintain or achieve a healthy weight.

Unarmed and ill prepared, college freshmen commonly practice unhealthy lifestyle habits. Surveys conducted on college freshmen and college students indicate that most college students don't eat the recommended servings of fruits and vegetables and often replace these low calorie nutritious foods with high-calorie, non-nutritive foods (Debate, 2001; Sax, 1997). These dietary choices may increase energy intake and contribute to weight gain. In addition to poor eating habits, many college freshmen also fail to meet the recommended daily physical activity requirement. A study on college freshmen's health trends showed that less than half of the female freshmen surveyed 
exercised six or more hours per week (Sax, 1997). Enrollment in daily physical education classes decreased from $42 \%$ in 1991 to $25 \%$ in 1995 , and only $19 \%$ of all high school students are physically active for 20 minutes or more in physical education classes on all days of the school week (US Department of Health and Human Services, 1996). This data suggests that many of the freshmen students entering college are unaccustomed to exercising on a regular basis.

\section{Previous Studies showing Freshman Weight Gain}

There are only a few studies that have been done to assess freshmen weight gain, and most of the studies have important limitations. The majority of the subjects were female and several of the studies had return rates far below 100\% (Graham and Jones, 2002; Hodge et al., 1993; Debate, 2001; Hojhosseini et al., 2003). Those that didn't return may have gained weight, which may have increased the mean weight gain among that sample population. Graham and Jones (2002) reported that the students who were most preoccupied with body image and weight gain were the students who participated in the entire study. The methods of assessing weight gain and body composition varied between studies. In one study subjects' heights and weights were self-reported (Debate, 2001). The data in this study may be inaccurate, because men tend to overestimate their height, females tend to underestimate their weight, and there was no standard method of measurement (e.g., the same scale). There is currently little data on the nature of how weight is gained in freshmen students. The only study that previously reported changes in body composition used skin-fold calipers; however, the site(s) measured were not specified (Graham and Jones, 2002). Because the methods used in this study were 
incomplete, the data are difficult to interpret. In addition, as with any study where subjects are being periodically tested for changes in weight and body composition, subjects may have been more aware of diet and changes in weight (Graham and Jones, 2002; Hojhosseini et al., 2003). In addition to changes in body weight and composition, few studies have looked at the amount of daily energy consumed and specific exercise habits of college freshmen. Levitsky et al. (2004) surveyed freshmen about eating habits (e.g., snacking, meals per day, whether or not they ate breakfast, average size of meals, and alcohol consumption); however, specific daily food consumption was not assessed. Levetsky et al. (2004) also queried freshmen about the number of times per week they exercised, but did not investigate their specific exercise practices (e.g., duration, intensity and type of exercise performed). Lastly, past freshmen weight gain studies only lasted 1 to 2 semesters; therefore, it is unclear whether this weight gain is long-term or transient (Graham and Jones, 2002; Hojhosseini et al., 2003; Hodge et al., 1993; Levetsky et al., 2004). Due to the above-mentioned limitations, weight gain among college freshmen remains poorly understood.

\section{Summary and Conclusions}

Weight gain in the United States is a growing problem in all age groups and the first year of college represents one specific time throughout a person's lifespan when an accelerated amount of weight is gained. Although presently there is no clear answer as to the exact amount of weight that is gained in the first year of college, it is clear that a noticeable amount of weight is gained and that this weight gain is highly variable. What is not clear is how this weight is gained, how lifestyle practices may "protect" or 
contribute to weight gain in this population, and whether or not this weight gain is longlasting or transient. For example, it is not clear from existing research whether changes in body composition and resting metabolic rate (RMR) take place as a result of changes in body weight. Moreover, previous studies on freshman weight gain have not clearly documented diet or physical activity. Both exercise and diet have been shown to effect weight loss and gain; therefore, these may be important factors in both assessing risk and developing prevention strategies. Therefore, the purpose of the present study is multifaceted. First, it will add to the existing literature on the amount of weight that is gained by college freshman and whether or not this weight gain is maintained into participants' sophomore year. Second, it will fill in the gaps on how weight is gained, assess changes in RMR, and document how dietary and exercise practices influence weight gain in this population. 
CHAPTER 2

JOURNAL ARTICLES 
Journal Article 1 


\begin{abstract}
A COMPARISON OF RESTING METABOLIC RATE (RMR) USING
MEASUREMENTS OF VENTILATED OXYGEN CONSUMPTION $\left(\mathrm{O}_{2}\right)$,

BIOELECTRICAL IMPEDENCE (BIA), METABOLIC BODY SIZE $\left(\mathrm{Kg}^{0.75}\right)$,

HARRIS-BENIDICT (HB-BEE), AND MIFFLIN / ST. JEOR (MSJ) EQUATIONS
\end{abstract}

\begin{abstract}
word count: 253 words
Text word count: 1635 words

Danielle L. Cook, MS

Graduate Student

Department of Nutrition and Food Science

San Jose State University

Tawni Holmes, $\mathrm{PhD}, \mathrm{RD} / \mathrm{LD}$

Assistant Professor

Nutrition, Dietetics and Food Management

University of Central Oklahoma

Clarie B. Hollenbeck, $\mathrm{PhD}$

Professor

Department of Nutrition and Food Science

San Jose State University
\end{abstract}

Address all correspondence to:

Clarie B. Hollenbeck, $\mathrm{PhD}$

Department of Nutrition and Food Science

San Jose State University

One Washington Square

San Jose, CA 95192-0058

Tel: (408) 924-3106

FAX: (408) 924-3114

Email: clariebh@casa.sjsu.edu 


\begin{abstract}
Objective: The purpose of this study was to compare five commonly used methods of measuring RMR in a sample size of young, healthy, college age males and females.

Design. The present study was a cross-sectional observational study.

Subjects/setting. A convenience sample of sixty-two young men and women with a mean age of $18.1 \pm 0.7$ yrs participated in these studies.

Main outcome measures. RMR was measured by ventilated $\mathrm{O}_{2}$ consumption and compared to estimates by BIA and three prediction equation calculations, metabolic body size $\left(\mathrm{kg}^{0.75}\right)$, HB-BEE, and MSJ.
\end{abstract}

Statistical analyses. Descriptive statistics and t-test for paired comparisons adjusted for multiplicity were used to compare different methods of measuring RMR. Pearson correlations were used to explore associative relationships among methods.

Results. $\mathrm{Kg}^{0.75}$ gave the highest prediction of $\mathrm{RMR}(1606 \pm 16 \mathrm{kcal})$ followed by $\mathrm{O}_{2}$ $(1580 \pm 19 \mathrm{kcal}), \mathrm{HB}-\mathrm{BEE}(1558 \pm 19), \mathrm{MSJ}(1506 \pm 22 \mathrm{kcal})$ and BIA $(1463 \pm 14 \mathrm{kcal})$ Although these methods yield significantly different estimates of RMR $(p<0.001)$, the quantitative differences were small and ranged from $1.6 \%$ to $8.9 \%$. Pearson correlations between $\mathrm{O}_{2}$ and $\mathrm{Kg}^{0.75}(\mathrm{r}=0.828 ; \mathrm{p}<0.001), \mathrm{O}_{2}$ and $\mathrm{BIA}(\mathrm{r}=0.681 ; \mathrm{p}<0.001)$, and MSJ and $\mathrm{BIA}(\mathrm{r}=0.841 ; \mathrm{p}<0.001)$ were statistically significant and very strong.

Conclusion. $\mathrm{Kg}^{0.75}$, HB-BEE, and MSJ and BIA all closely predicts RMR estimated by $\mathrm{O}_{2}$ 
Application. The equations for measurement of RMR, which only require a scale, stadiometer and a calculator, can provide reasonable estimates of RMR when performed in a less structured setting. 


\section{Introduction}

Overweight and obesity has increased dramatically in the United States in the past 30 years. According to the 1999-2000 National Health Nutrition Examination Survey (NHANES) an estimated $64 \%$ of adults and $15 \%$ of children ages $6-19$ years old in the United States are either overweight or obese (1). Body Mass Index (BMI), which is a measure of weight in $\mathrm{kg}$ compared to height in meters squared $\left(\mathrm{kg} / \mathrm{m}^{2}\right)$, was used to classify overweight and obesity. Overweight is identified as a BMI of 25 to $29.9 \mathrm{~kg} / \mathrm{m}^{2}$ and obesity is defined as a BMI of $30 \mathrm{~kg} / \mathrm{m}^{2}$ and above.

Obesity is a serious health risk, which has created considerable concern among clinicians and health experts. Approximately 300,000 annual deaths are attributed to obesity (2). Studies have linked excess weight to an increased risk of numerous health conditions such as cardiovascular disease and type 2 diabetes $(3,4,5)$.

Weight loss of as little as $5-15 \%$ of a person's initial body weight can decrease an overweight person's risk of developing weight related diseases (6). An important factor in weight loss is creating a negative energy balance. In order to successfully and safely achieve this, an accurate assessment of total daily energy expenditure must be determined. Total daily energy expenditure (TEE) is dependent on the following three variables: resting metabolic rate (RMR), thermic effect of food (TEF) and physical activity (7). TEF accounts for approximately $10-15 \%$ of 24 -hour energy expenditure (EE) and varies depending on diet (8). Physical activity is also highly variable between individuals and may contribute between $20-30 \%$ of TEE (8). Because TEF and physical activity between individuals is so variable from day to day, RMR is most frequently used 
as a predictor of 24-hour EE. RMR accounts for approximately $65-70 \%$ of TEE, and is best predicted by lean body mass (LBM) (8-13).

The "Gold Standard" for determining resting metabolic rate (RMR) is direct calorimetry. However, this procedure is expensive and requires specialized facilities for proper determination. As a result, indirect methods that allow reasonably accurate estimates of RMR have been developed. Several indirect methods for measuring and predicting RMR exist. Two widely used methods for estimating RMR are the measurement of ventilated oxygen consumption $\left(\mathrm{O}_{2}\right)$ and estimates of lean body mass and body cell mass using bioelectrical impedance (BIA). Several prediction equations for estimating RMR have also been developed (8-10). Most equations only require age, weight, height and gender in the calculation. Although these methods do not require expensive equipment and trained technicians, studies have suggested that these equations are inaccurate when compared to measured estimates of RMR $(11,12,14-17)$. The purpose of this study was to compare four different, easily performed, less expensive, commonly used methods of measuring RMR in a sample size of young, healthy, males and females.

\section{Methods and Procedures}

\section{Subjects and Study Design}

A convenience sample of sixty-two young men $(n=23)$ and women $(n=39)$ with a mean age of $18.1 \pm 0.7$ yrs participated in these studies. Their clinical and demographic characteristics are presented in Table 1 . The study population was ethnically diverse and similar to that ethnic composition of San Jose State University. Their mean BMI (23.1 \pm 
$3.7 \mathrm{~kg} / \mathrm{m}^{2}$ ) was well within the normal, healthy range. The study was designed as a longitudinal study completed over the course of one 16-week semester. Participants reported to the Nutrition and Metabolic Laboratory at San Jose State University between 8:00 am and 5:00 pm every 5-6 weeks (total of 3 visits) in a post absorptive state ( $>2 \mathrm{hr}$ from last meal), rested ( $>2 \mathrm{hrs}$ since exercising) and well hydrated. Individuals were weighed without shoes and in light clothing using a laboratory stadiometer at each visit. Measurements of RMR were estimated by ventilated $\mathrm{O}_{2}$ consumption (Body Gem Health Tech Inc.) on the first and the last visit (16 weeks apart). The BodyGem is a small handheld device fitted with a SCUBA type mouthpiece. The subject sits in a seated position and breathes through the apparatus for 12-15 minutes. Oxygen is captured in the device and the BodyGem uses this data to compute a RMR.

In addition, 35 of the individuals also had RMR determined by BIA (BIA; Physiological Event Analyzer (PEA), RJL Systems) on all three days of testing. BIA requires 2 EKG-type electrodes to be placed 2-3 cm apart on one hand and one foot on the same side of the body. Subjects lie supine on a table during measurements. Resistance to flow of a small electrical current is measured by the BIA, and this data is used to estimate total body water and lean body mass. The BIA uses height, weight, and body composition to compute a RMR. Finally, three prediction equations for estimating RMR were used: Metabolic body size $\left(\mathrm{RMR}=\mathrm{Kg}^{0.75} \mathrm{X} 70\right)(9)$, Harris-Benedict (Females: $655+9.56 \mathrm{~W} \mathrm{~kg}+1.85 \mathrm{H} \mathrm{cm}-4.68 \mathrm{~A}$; Males: $66.5+13.75 \mathrm{~W}+5.0 \mathrm{H}-6.78$ A) (10), and Mifflin / St Jeor (Females: $655+9.56 \mathrm{~W} \mathrm{~kg}+1.85 \mathrm{H} \mathrm{cm}-4.68 \mathrm{~A}$; Males: $66.5+13.75 \mathrm{~W}+5.0 \mathrm{H}-6.78 \mathrm{~A})(8)$. Subjects volunteered to participate in the study 
and provided informed written consent. Approval for the study was obtained from the Human Subjects Committee at San Jose State University.

\section{Variability of BIA and RMR Measurements}

BIA measurements were repeated ten times, one minute apart in nine individuals to determine an intra-assay coefficient of variation (repeated measurement within an individual) for body composition. This same method was repeated one week later in the same nine individuals to assess inter-assay coefficient of variation for body composition (repeated measurements between different days). Inter-assay variation for BIA was 1.1 \pm $0.9 \%$, while inter-assay variation was $0.3 \pm 0.2 \%$.

Measurements of RMR were performed three times during the same visit in 13 individuals to determine an intra-assay coefficient of variation in RMR. Intra-assay coefficient of variability in RMR was $4.6 \pm 2.5 \%$. Fasting RMR was repeated in 8 individuals on a stable diet at three intervals over a period of two weeks, on day 1,5 and 14 for the determination of inter-assay variability (repeated measurements on different days). The inter-assay coefficient of variability was $2.3 \pm 0.7 \%$.

\section{Statistical Analysis}

Descriptive statistics were used to describe subjects. A t-test for paired comparisons adjusted for multiplicity was used to compare different methods of measuring RMR. Pearson correlations were used to explore associative relationships between methods. All analyses were performed using a SPSS software version 10.0 for Macintosh. Data are expressed as mean \pm standard deviation and statistical significance was set at $\mathrm{p}<0.05$. 


\section{Results}

The results (Table 2) indicated that $\mathrm{Kg}^{0.75}$ gave the highest prediction of RMR $(1606 \pm 16 \mathrm{kcal})$ followed by $\mathrm{O}_{2}(1580 \pm 19 \mathrm{kcal})$, Harris-Benedict $(1558 \pm 19), \mathrm{Mifflin} / \mathrm{St}$. Jeor $(1506 \pm 22 \mathrm{kcal})$ and BIA $(1463 \pm 14 \mathrm{kcal})$. Although these methods yield significantly different estimates of $R M R(p<0.001)$, the quantitative differences were very small and ranged from $1.6 \%\left(\mathrm{O}_{2}\right.$ vs. $\left.\mathrm{Kg}^{0.75}\right)$ to $8.9 \%\left(\mathrm{Kg}^{0.75}\right.$ vs. $\left.\mathrm{BIA}\right)$. Pearson correlations (Table 3 and Figure 1) between $\mathrm{O}_{2}$ and $\mathrm{Kg}^{0.75}(\mathrm{r}=0.828 ; \mathrm{p}<0.001), \mathrm{O}_{2}$ and $\operatorname{BIA}(\mathrm{r}=0.681 ; \mathrm{p}<0.001)$, and MSJ and BIA $(\mathrm{r}=0.841 ; \mathrm{p}<0.001)$ were statistically significant and very strong.

\section{Discussion}

Results from the present study indicate that all three methods provide reasonably similar estimates, with strong significant correlations among the 5 techniques. It is important to note that there is no clear, consistent protocol or definition among scientific literature for measuring RMR. For example, Frankenfield et al., Case et al., Heymsfield et al., Owen et al., required subjects to fast for 12 hours, abstain from exercise for 12-24 hours, and performed RMR measurements in the morning (12-17). Foster et al. required subjects to fast for only 6 hours and measured subjects in the early afternoon (11). Trone et al. measured RMRs in the late afternoon and required subjects to fast for 4 hours and abstain from exercise for at least 4 hours (18).

The thermic effect of food in healthy lean women is highest at 30 and 90 minutes and is completed by 210 minutes on average (16). Data from our laboratory define peak rise in energy expenditure between $40-75$ minutes with return to baseline RMR by 105 
minutes post challenge. Subjects in the present study fasted for 2 or more hours, thus, the TEF would be expected to have had little effect on RMR in these individuals. In addition to the thermic effect of food, exercise may have also positively affected subjects RMR. A $15-50 \%$ elevation in energy expenditure above RMR during the recovery period post exercise, commonly referred to as excess post exercise oxygen consumption (EPOC), has been observed $(19,13)$. Data from a small study of trained females demonstrated that RMR remained significantly elevated above resting levels for 1 hour, which resulted in an additional expenditure of approximately 25 extra calories (19). Melanson et al. observed similar findings in EPOC in men (20). Subjects in the present study were asked to abstain from exercise for a minimum of 2 hours; therefore, RMR was also probably not substantially affected by exercise in our study population. Nevertheless, since the present study only required subjects to fast for 2 hours and abstain from exercise for 2 hours, and the measured values for RMR may have been slightly overestimated.

The study design used in this research has important applications. The two methods we used to measure RMR do not require a highly trained technician to use and are therefore suitable for use outside of a research setting (20). Many health clubs and dieticians use these methods informally in practice daily. These methods both require that specific protocols be followed in order to assure accuracy; however, these protocols are rarely followed. The protocol used in the present study more closely mimics the metabolic state of most subjects measured outside of a research setting. In addition, although the BodyGem and BIA are less expensive methods than more widely accepted clinically research methods, they still require a relatively substantial financial investment. 
Our data suggests that $\mathrm{Kg}^{0.75}$, Harris-Benedict, and Mifflin / St. Jeor, which only require a scale, a stadiometer and a calculator, closely predicts RMR estimated by $\mathrm{O}_{2}$ when performed in a less structured setting. Although the present study does not allow these methods to be compared with "true" RMR, the results indicate that all five methods provide reasonably similar estimates, with strong significant correlations among the techniques and, thus, provide useful tools for estimating caloric recommendations to healthy, young adults. These estimates can then be used to prescribe appropriate caloric recommendations for young healthy persons seeking weight loss. Finally, additional comparisons among these methods are required to better assess the reliability of these calculations in other age groups, obese individuals, and critically ill patients. 


\section{Acknowledgements}

This research was supported by a Zellmer Scholarship Trust Fund Grant from the California Dietetic Association, a Small Research Grant Award from the College Applied Sciences and Arts at San Jose State University, and a Research Assistance Award through the Circle of Friends in the Department of Nutrition and Food Science at San Jose State University. The authors are especially grateful to all of the participants who volunteered their time for this study. 


\section{References}

1. Center for Disease Control and Prevention, Atlanta. Retrieved July 22, 2004, from http://www.cdc.gov/nccdphp/dnpa/obesity/contributing_factors.htm

2. Allison, D., Fontaine, K., Manson, J., Stevens, J., VanItallie, T. (1999). Annual deaths attributed to obesity in the United States. Journal of the American Medical Association, 282 (16), 1530-1538.

3. U.S. Department of Health and Human Services (1996). A report of the Surgeon General: Physical Activity and Health. Retrieved August 5, 2004, from http://www.surgeongeneral.gov/topics/obesity/calltoaction/fact_glance.htm

4. Stein, C., Colditz, G. (2004). The epidemic of obesity. J Clin Endocrinol Metab, 89, 2522-2525.

5. Bray, G. (2004). Medical consequences of obesity. The Journal of Clinical Endocrinology \& Metabolism, 89(6), 2583-2589.

6. Pescatello, L., VanHeest, J. (2000). Physical activity mediates a healthier body weight in the presence of obesity. British Journal of Sports Medicine, 34, 86-93.

7. Matvienko, O., Lewis, D.S., Schafer, E. (2001). A college nutrition science course as an intervention to prevent weight gain in female college freshmen. Journal of Nutrition Education, 33, 95-101.

8. Mifflin, M, St. Jeor, S., Hill, L., Scott, B., Daugherty, S., O’Koh, Y. (1990). A new predictive equation for resting energy expenditure in healthy individuals. The American Journal of Clinical Nutrition, 51, 241-247.

9. Garrow, JS. (1987). Energy balance in man. Am J Clin Nut, 45, 1114-1119. 
10. Harris, J, Benedict, F. (1919). A biometric study of basal metabolism in man. Publication 279. Washington, DC: Carnegie Institute.

11. Foster, G., Wadden, T., Mullen, J., Stunkard, A., Wang, J., Feurer, I., Pierson, R., Yang, M., Presta, E., Van Itallie, T., Lemberg, P., Gold, J. (1988). Resting energy expenditure, body composition, and excess weight in the obese. Metabolism (37), 5, 467-472.

12. Owen, O., Holup, J., D’Alessio, D., Craig, E., Polansky, M., Smalley, K., Kavle, E., Bushman, M., Owen, L., Mozzoli, M., Kendrick, Z., Boden, G. (1987). A reappraisal of the caloric requirements of men. American Journal of Clinical Nutrition (46), 87585.

13. Brooks, G., Fahey, T., White, T., Baldwin, K. (2000). Exercise physiology: Human bioenergetics and its applications $\left(3^{\text {rd }}\right.$ ed.). Mountain View, CA: Mayfield Publishing Company.

14. Frankenfield, D., Rowe, W., Smith, S., Cooney, R. (2003). Validation of several established equations for resting metabolic rate in obese and nonobese people. Journal of the American Dietetic Association (103), 1152-1159.

15. Daly, J., Heymsfield, S., Head, A., Harvey, L., Nixon, D., Katzeff, H., Grossman, G. (1985). Human energy requirements: overestimation by widely used prediction equation. The American Journal of Clinical Nutrition (42), 1170-1174.

16. Owen, O., Kavle, E., Owen, R., Polansky, M., Caprio, S., Mozzoli, M., Zebulon, V., Kendrick, Z., Bushman, M., Boden, G. (1986). A reappraisal of the caloric requirements in healthy women. American Journal of Clinical Nutrition (44), 1-19. 
17. Case, K., Brahler, J., Heiss, C. (1997). Resting energy expenditures in Asian women measured by indirect calorimetry are lower than expenditures calculated from prediction equations. Journal of the American Dietetic Association, 97(11), 12881292.

18. Nieman, D., Trone, G., Austin, M. (2003). A new handheld device for measuring resting metabolic rate and oxygen consumption. Journal of the American Dietetic Association, 103, 588-593.

19. Binzen, C., Swan, P., Manore, M. (2001). Postexercise oxygen consumption and substrate use after resistance exercise in women. Medicine $\&$ Science in Sports \& Exercise. Retrieved June 20, 2004, from http://www.acsm-msse.org

20. Melanson, E., Sharp, T., Seagle, H., Donahoo, W., Grunwald, G., Peters, J., Hamilton, J., Hill, J. (2002). Resistance and aerobic exercise have similar effects on 24-h nutrient oxidation. Medicine \& Science in Sports \& Exercise, 1793-1800. 
Table 1 Clinical and Demographic Characteristics of 62 Young Healthy Men and Women Undergoing Testing for Resting Metabolic Rates

Clinical Characteristics

Age (Year)

Gender

Weight $(\mathrm{kg})$

Height $(\mathrm{cm})$

Body Mass Index $\left(\mathrm{kg} / \mathrm{m}^{2}\right)$

Demographic Characteristics

Asian and Pacific Islander

Caucasian

African American

Hispanic

Other

$$
\underline{\mathrm{n}=62}
$$

$\underline{\mathrm{n}=35}$

$18.1 \pm 0.7$

$17.9 \pm 0.4$

$23 \mathrm{M} / 39 \mathrm{~F}$

$19 \mathrm{M} / 16 \mathrm{~F}$

$65.1 \pm 14.2$

$66.0 \pm 13.2$

$167.2 \pm 9.3$

$168.6 \pm 9.8$

$23.1 \pm 3.7$

$23.1 \pm 3.4$
$44 \%$

$30 \%$

$11 \%$

$11 \%$

$4 \%$
$51 \%$

$28 \%$

$4 \%$

$26 \%$

$0 \%$ 
Table 2 Estimated Resting Metabolic Rate for Ventilated Oxygen Consumption $\left(\mathrm{O}_{2}\right)$, Bioelectrical Impedance (BIA), Metabolic Body Size $\left(\mathrm{Kg}^{0.75}\right)$, Harris-Benedict Equations (HB-BEE), and Mifflin / St. Jeor (MSJ)

\begin{tabular}{|l|c|}
\hline Method & RMR (kcal) \\
\hline $\mathrm{O}_{2}$ & $1573 \pm 30$ \\
\hline $\mathrm{BIA}$ & $1450 \pm 22$ \\
\hline $\mathrm{Kg}^{0.75}$ & $1598 \pm 23$ \\
\hline Harris-Benedict & $1594 \pm 23$ \\
\hline Mifflin / St Jeor & $1506 \pm 22$ \\
\hline
\end{tabular}


Table 3 Correlation Coefficients Between Ventilated Oxygen Consumption $\left(\mathrm{O}_{2}\right)$, Bioelectrical Impedance (BIA), Metabolic Body Size $\left(\mathrm{Kg}^{0.75}\right)$, Harris-Benedict (HBBEE), and Mifflin / St. Jeor (MSJ) Equations

\begin{tabular}{|l|c|c|}
\hline & $\begin{array}{c}\text { Correlation Coefficient } \\
(\mathrm{r})\end{array}$ & $\mathrm{P}$ \\
\hline $\mathrm{O}_{2}$ vs $\mathrm{Kg}$ & & \\
\hline $\mathrm{O}_{2}$ vs $\mathrm{HB}-\mathrm{BS}$ & 0.853 & 0.001 \\
\hline $\mathrm{O}_{2}$ vs MSJ & 0.782 & 0.001 \\
\hline $\mathrm{O}_{2}$ vs BIA & 0.777 & 0.001 \\
\hline $\mathrm{Kg}^{0.75}$ vs MSJ & 0.681 & 0.001 \\
\hline $\mathrm{Kg}^{0.75}$ vs HB & 0.932 & 0.001 \\
\hline $\mathrm{Kg}^{0.75}$ vs BIA & 0.911 & 0.001 \\
\hline $\mathrm{HB}$ vs MSJ (female) & 0.713 & 0.001 \\
\hline $\mathrm{HB}$ vs MSJ (male) & 0.995 & 0.001 \\
\hline $\mathrm{BIA}$ vs MSJ & 0.981 & 0.001 \\
\hline BIA vs HB-BEE & 0.841 & 0.001 \\
\hline
\end{tabular}




\section{LEGEND FOR FIGURE 1}

Figure 1. Correlations Between Ventilated Oxygen Consumption $\left(\mathrm{O}_{2}\right)$, Bioelectrical

Impedance (BIA), Metabolic Body Size $\left(\mathrm{Kg}^{0.75}\right)$, Harris-Benedict (HB-BEE), and Mifflin / St. Jeor (MSJ) Equations RMR

BIA_RMR = bioelectic impedance apparatus RMR

bodygem $\mathrm{RMR}=\mathrm{O}_{2}$ consumption $\mathrm{RMR}$

MBSRMR = metabolic body size RMR

HBRMR = Harris-Benedict RMR 
a

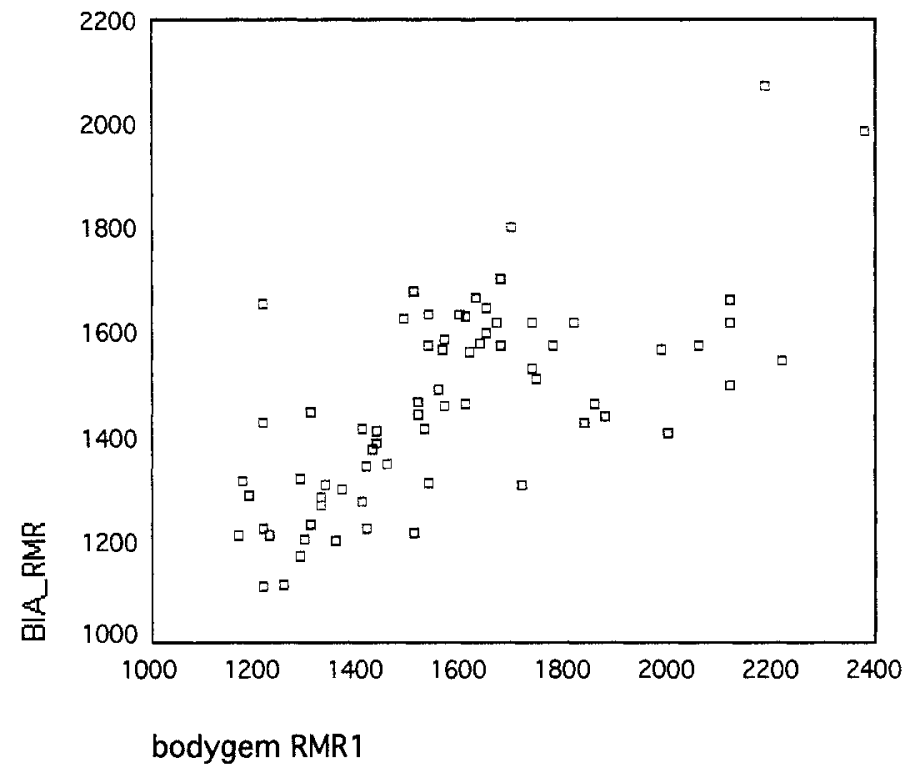

b

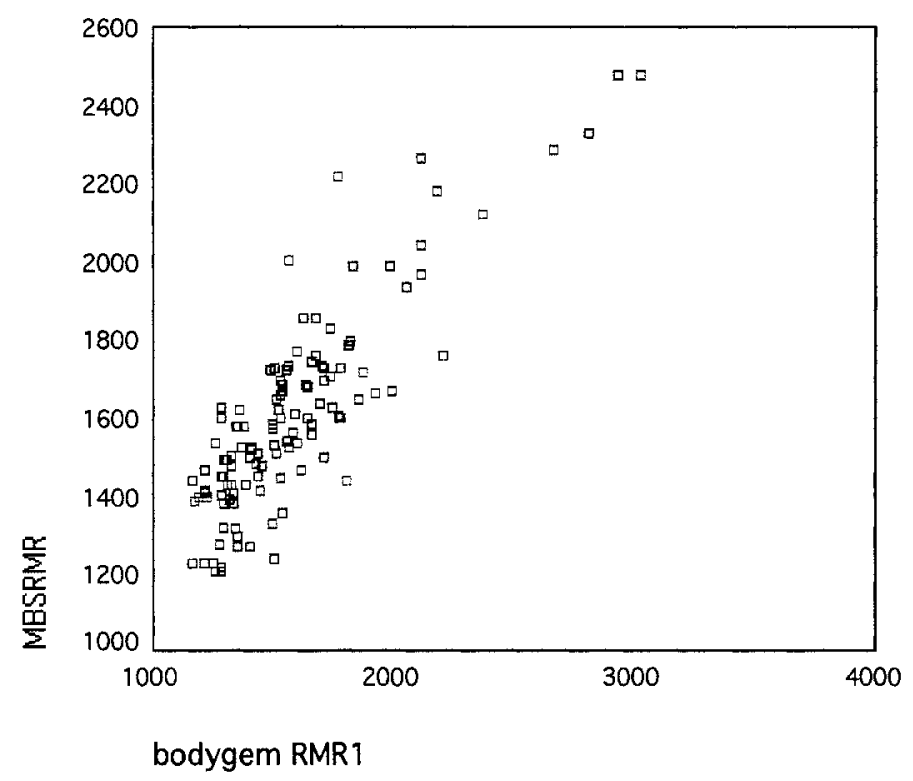


c

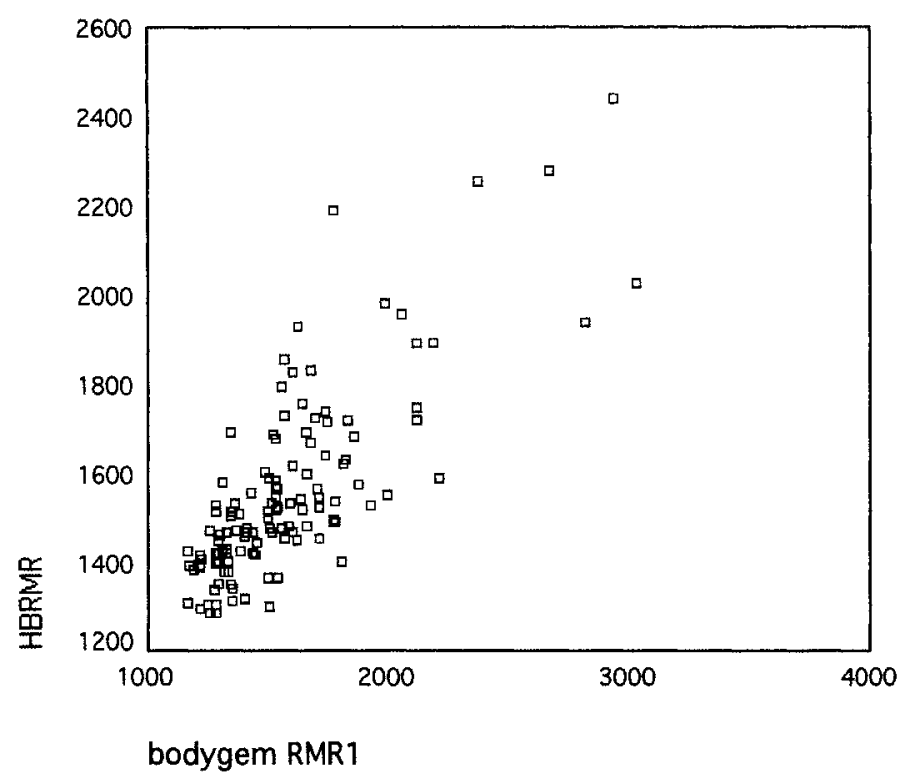

d

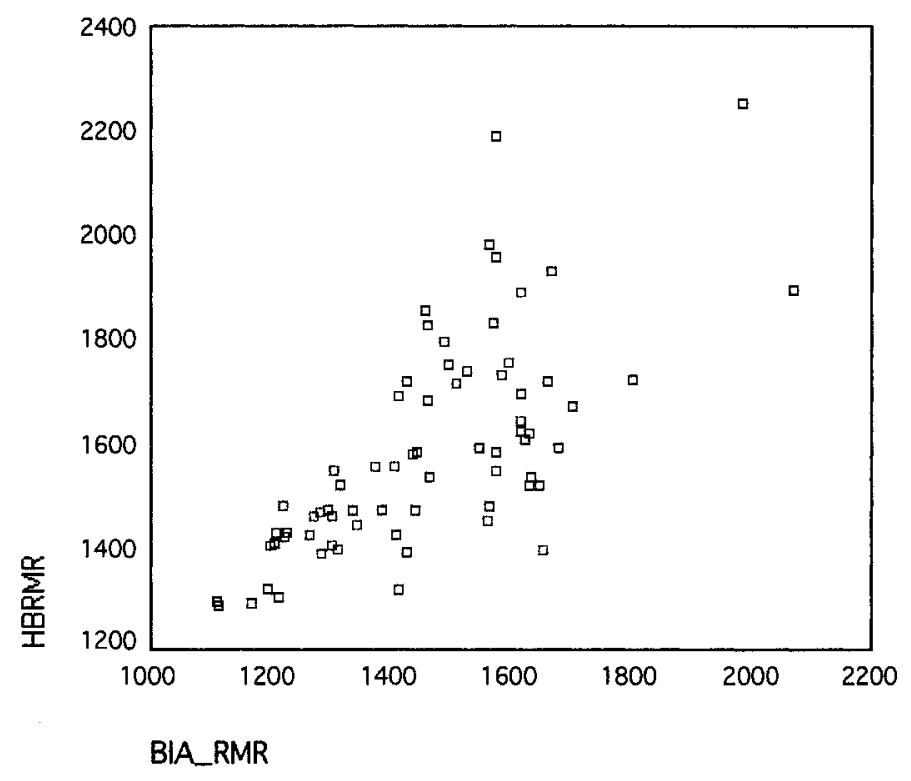


e

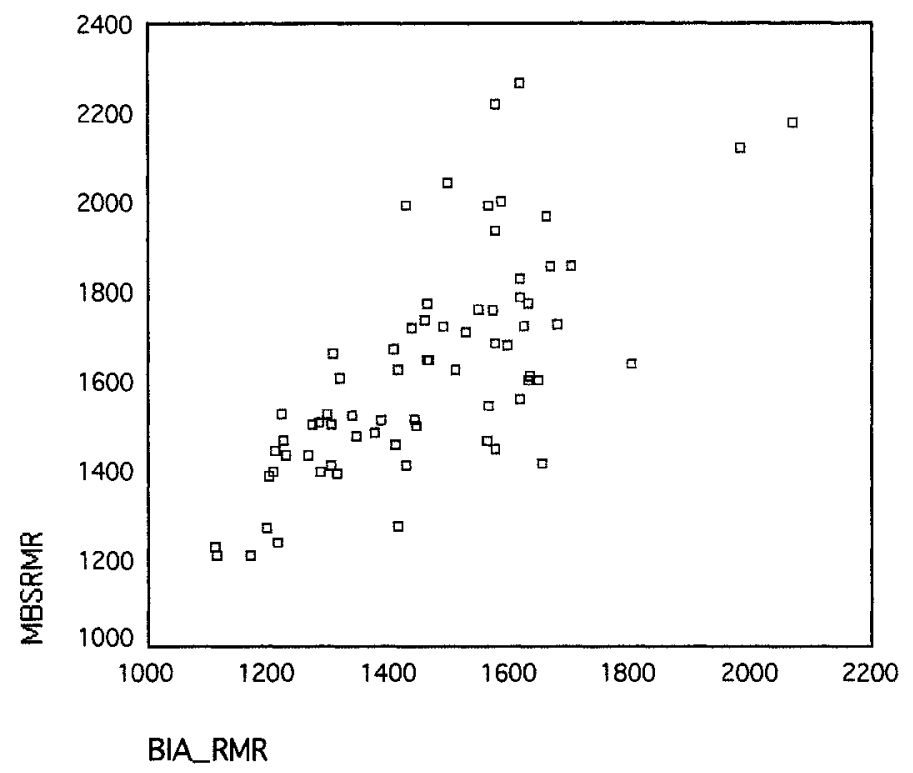

f

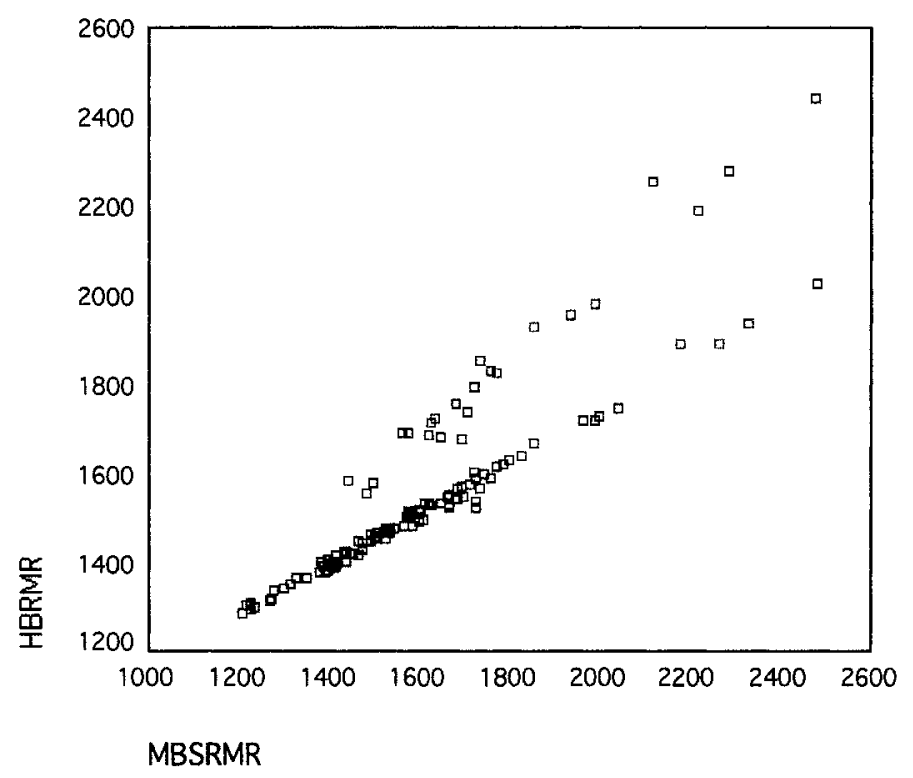


Journal Article 2 
CHANGES IN BODY WEIGHT, BODY COMPOSITION, RESTING METABOLIC

RATE AND PHYSICAL ACTIVITY IN COLLEGE FRESHMEN

Danielle L Cook, MS

Graduate Student

Department of Nutrition and Food Science

San Jose State University

Tawni Holmes, $\mathrm{PhD}, \mathrm{RD} / \mathrm{LD}$

Assistant Professor

Nutrition, Dietetics and Food Management

University of Central Oklahoma

Kathryn Sucher, DSc, RD

Professor

Department of Nutrition and Food Science

San Jose State University

Clarie B. Hollenbeck, $\mathrm{PhD}$

Professor

Department of Nutrition and Food Science

San Jose State University

Address all correspondence to:

Clarie B. Hollenbeck, $\mathrm{PhD}$

Department of Nutrition and Food Science

San Jose State University

One Washington Square

San Jose, CA 95192-0058

Tel: (408) 924-3106

FAX: (408) 924-3114

Email: clariebh@casa.sjsu.edu 


\section{ABSTRACT}

Overweight and obesity has increased dramatically in the United States in the last 30 years. The first year of college has been shown to be a time in one's life when a substantial amount of weight is gained at an accelerated rate. The purpose of the present study is to investigate changes that occurred in body weight, body composition, and RMR, how diet and physical activity practices affected these changes in newly enrolled college freshmen, and whether or not this weight gain is long-lasting or transient. A convenience sample of 63 male and female freshmen students attending San Jose State University were recruited for the present study. The study was designed as a longitudinal study, which was completed over the course of one semester (16 weeks). Subjects' heights, weights, resting metabolic rate, body composition, dietary habits, and exercise practices were assessed throughout the semester. A subset of 29 male and female freshmen students returned for a follow-up visit to assess changes in weight at the end of one year. The results showed that both males and females in the study gained an average of 2.5 pounds during the first semester. Forty-four $(70 \%)$ of the participants gained weight, with $24(38 \%)$ of the individuals gaining 5 or more lbs during the study period. Sixteen (25\%) of the participants lost weight and in 3 individuals' weights did not change. There were significant changes in body composition in females $(p=0.002)$, but not in males, with females increasing fat mass from $29.4 \pm 1.1 \%$ at baseline to $31.5 \pm 1.0$ $\%$ by the end of the study. There were no significant changes in RMR, total energy, or macronutrient intake for males or females during the study. Males and females reported similar activity levels. Seven (37\%) males and $8(47 \%)$ females met or exceeded the 
ACSM minimum exercise guidelines for healthy adults over the entire semester. Individuals who met the American College of Sports Medicine (ACSM) minimum guidelines for exercise gained a mean of $0.8 \pm 1.1 \mathrm{lbs}$, whereas individuals who did not meet ACSM exercise guidelines gained an average of $3.1 \pm 0.9 \mathrm{lbs}$. Finally, body weights in a representative sample of 29 of the 63 individuals studied (46\%) returned to toward initial baseline body weights and no significant differences were noted in mean body weight at 1 year. The present study demonstrates that a significant amount of weight is gained upon entering the first year of college and this weight gain is variable; however, this weight gain appears to be transient in nature. The data in this study demonstrates that weight gain in some individuals can be substantial and females seem to gain their weight in fat mass. The findings in this study also suggest that a small amount of exercise may be protective against initial weight gain in this population.

KEY WORDS: Freshman weight gain, resting metabolic rate, body composition, physical activity and weight maintenance 


\section{INTRODUCTION}

An estimated $64.5 \%$ of adults are overweight $\left(\mathrm{BMI} \geq 25.0 \leq 29.9 \mathrm{~kg} / \mathrm{m}^{2}\right)$ and $30.5 \%$ of adults are clinically defined as obese (BMI $\left.\geq 30 \mathrm{~kg} / \mathrm{m}^{2}\right)$ in the United States (1). This represents an $8 \%$ increase in less than a decade (1). Although success at maintaining weight loss is possible, increasing trends of overweight and obesity suggest that long-term weight loss may be unsuccessful (2). It has been estimated that 90 to $95 \%$ of persons who lose weight regain their weight (3). Because current weight loss programs have little long-term success and weight gain is rarely reversed, prevention of weight gain is critical in weight control. Targeting important times when weight is gained throughout the lifespan and identifying who is at the greatest risk for gaining weight are important factors in slowing the rate of obesity in the United States.

The first year of college represents an important life-style change that is often accompanied by weight gain $(4,5,6)$. There is a well-established belief that freshmen gain approximately 15 pounds during their first year of college. This notion is commonly referred to as "The Freshman 15." Although research indicates that weight is gained during the first year of college, the amount of weight that is gained varies. Lifestyle practices that may "protect" or lead to weight gain in this population and how weight is gained are incomplete. For example, it is not clear from existing research whether changes in body composition and resting metabolic rate (RMR) take place as a result of changes in body weight. In addition, previous studies on freshmen weight gain have not investigated specific changes in diet or physical activity and how these may affect changes in body weight. These may be important factors in both assessing risk and 
developing successful prevention strategies. Therefore, the purpose of the present study was to determine changes that occurred in body weight, body composition and RMR, and how diet and physical activity practices affected these changes in newly enrolled college freshmen.

\section{METHODS AND PROCEDURES}

\section{$\underline{\text { Subject Population }}$}

A convenience sample of 63 male and female freshmen students attending San Jose State University were recruited for the present study. A subset of 29 male and female freshmen students was followed for their entire first year of college. Changes in diet, physical activity habits, and body composition of freshmen students were emphasized as the purpose of the study in order to avoid a focus on changes in body weight. Preliminary demographic characteristics were documented for each subject and coded by the last 4 digits of their student ID numbers. All additional data collected was coded in the same manner in order to make comparisons throughout the semester while still maintaining individual confidentiality.

\section{Experimental Design}

The study was designed as a longitudinal study, which was completed over the course of one semester ( 16 weeks). An additional subset of 29 of the original participants returned at 1 year for follow-up. Approval for the study was obtained from the Human Subjects Committee at SJSU. An orientation held in the Department of Nutrition and Food Science was offered to prospective volunteers during the first 3 weeks of the fall semester. During this meeting, the study was described to participants and general 
questions concerning the protocol were answered. In addition, short presentations, which offered the same information as the orientation meetings, were performed in classes containing predominantly freshmen. Individuals who volunteered to take part in the study signed an informed consent approved by the Human Subjects Committee at San Jose State University. After obtaining informed consent, investigators demonstrated the proper procedure for completing the 3-day diet record and food frequency questionnaire, and participants were then scheduled for an initial visit (clinic visit 1).

Subjects' baseline height, weight, resting metabolic rate, body composition, 3-day diet records, and food frequency questionnaires were assessed in the initial study visit. One of the study investigators queried participants about their responses to their 3-day dietary record and food frequency questionnaire to clarify responses and eliminate potential ambiguity. All study investigators received the same training and followed the identical protocol for each participant. A subset of 36 of the participants was also asked to fill out a detailed survey concerning their present and past physical activity. Upon completing the exercise survey, subjects were scheduled for two additional clinic visits, one between weeks 7 and 8 (clinic visit 2) and again between weeks 14 and 16 (clinic visit 3). Body weight, body composition and 3-day diet record were repeated at clinic visit 2 and 3. Resting metabolic rate, food frequency questionnaire and the exercise survey were repeated only during clinic visit 3 . Finally, a subset of 29 participants was weighed at the beginning of their sophomore year (1-year follow-up).

Participants were asked to abstain from consuming any food or drink other than water or engaging in any exercise for a minimum of 2 hours prior to their scheduled 
appointment time. Subjects who exercise or ate within 2 hours of their appointment were rescheduled. The importance of proper hydration for accurate measurements of body composition was explained to all subjects. Hydration was measured during body composition analysis at each visit and subjects were rescheduled if not properly hydrated (between 50\%-70\%). All subjects were appropriately hydrated, and the mean hydration percentages during the three measurement periods were $54 \%, 54 \%$ and $53 \%$, respectively.

\section{Determination of Body Composition / BMI / Resting Metabolic Rate (RMR)}

Body composition was estimated by whole body bioelectrical impedance (BIA; Physiological Event Analyzer (PEA), RJL Systems). Body Mass Index (BMI) was calculated by dividing subject's weight in $\mathrm{kg}$ by their height in meters squared $\left(\mathrm{kg} / \mathrm{m}^{2}\right)$. RMR was calculated by measurements of ventilated oxygen consumption while seated and at rest (Body Gem, Health Tech Inc.) (7). The device was fitted with a SCUBA type mouthpiece, which is placed in the individual's mouth. The individual breathed through the device continuously until steady state oxygen consumption was reached. Sensors in the device measure oxygen consumption and ventilation. Oxygen consumption at rest is used as a basis to calculate RMR. Each individual used a new mask for each measurement taken.

Variability of BIA and RMR Measurements

BIA measurements were repeated ten times, one minute apart in nine individuals to determine an intra-assay coefficient of variation (repeated measurement within an individual) for body composition. This same method was repeated one week later in the 
same nine individuals to assess inter-assay coefficient of variation for body composition (repeated measurements between different days). Inter-assay variation for BIA was $1.1 \pm$ $0.9 \%$, while inter-assay variation was $0.3 \pm 0.2 \%$.

Measurements of RMR were performed three times during the same visit in 13 individuals to determine an intra-assay coefficient of variation in RMR. Intra-assay coefficient of variability in RMR was $4.6 \pm 2.5 \%$. Fasting RMR was repeated in 8 individuals on a stable diet at three intervals over a period of two weeks, on day 1, 5 and 14 for the determination of inter-assay variability (repeated measurements on different days). The inter-assay coefficient of variability was $2.3 \pm 0.7 \%$.

\section{3-Day Dietary Records}

Three-day diet records were collected at each of the three clinic visits. The dietary records were recorded over three days including two weekdays and one weekend day, excluding Friday. Specifically, records were kept Wednesday, Thursday and Saturday, or Sunday, Monday and Tuesday. Participants were asked to record estimated portions of all food and to include brand names of items when possible, to indicate which foods were consumed in restaurants and which were prepared at home, and were queried about the relative amounts of ingredients in all combinations foods (burritos, pizza, casseroles, etc). All dietary records were checked by the investigators during each visit for completeness, clarity, and accuracy. Recorded intakes of food were analyzed, using both USDA food guide pyramid and by computer-based analysis using the Food Processor Nutrition and Fitness software (version 8.0, 2002, ESHA Research, Salem, OR). 


\section{Exercise Survey}

Exercise was assessed with a close-ended survey. Participants were queried about the following: Number of days per week they exercise (1-7), level of intensity (1-10 from exercise intensity scale), duration ( $>20$ minutes or $<20$ minutes) type of exercise (aerobic, anaerobic, both or other), how long they have been doing this exercise $(1-4,5-8$, or 9-12 weeks), whether or not they played a sport in high school, whether or not they took physical education in high school, and if they presently participated in an organized sport. Individuals were assessed by whether or not they met or exceeded the American College of Sports Medicine (ACSM) aerobic fitness recommendations (8). ACSM recommends that healthy adults should perform a minimum of 20 minutes of moderate to vigorous aerobic exercise on 3 or more days a week (8).

\section{$\underline{\text { Statistical Analysis }}$}

Descriptive statistics, which included $t$ tests for paired comparisons and general linear model (GLM) and Pearson's Bivariate Regression Analysis, were performed using SPSS software version 10.0 for Macintosh. All data are shown as mean \pm standard deviation (SD) and statistical significance was set at $\mathrm{p}<0.05$. Males and females were analyzed separately due to gender differences reflected in data collection and the known differences in body composition.

\section{RESULTS}

The clinical characteristics of study participants are presented in Table 1. There were approximately twice as many females $(n=40)$ than males $(n=23)$. The mean age was $18 \pm 0.1$ years. The mean body weight was $165.9 \pm 34.3$ in males and $129.2 \pm 19.5$ 
in females. The mean BMI was $24.6 \pm 4.3$ in males and $22.5 \pm 2.8$ in females. The clinical characteristics of the 29 individuals who completed the 1-year follow-up evaluation (Table 1) were not significantly different from the initial study population; however, males and females were more equally representative in this sampling. Fourteen of the $63(22.5 \%)$ students could be clinically defined as overweight $(13 \%$; BMI $\geq 25.0 \leq$ $\left.29.9 \mathrm{~kg} / \mathrm{m}^{2}\right)$ or obese $\left(9.5 \%\right.$; BMI $\left.>30.0 \mathrm{~kg} / \mathrm{m}^{2}\right)$, while only one individual $(1.5 \%)$ was underweight (BMI $<18.5 \mathrm{~kg} / \mathrm{m}^{2}$ ). The majority of students (48 out of $63 ; 76 \%$ ) were normal body weight (BMI $\geq 18.5 \leq 24.9 \mathrm{~kg} / \mathrm{m}^{2}$ ). The study population was ethnically diverse, with 31 of the 63 participants (49.2\%) Asian and Pacific Islander, 17 (27\%) Caucasian, 11 (18\%) Hispanic and 4 (6\%) African American. The ethnic distribution within the study population represents the ethnic distribution within the student population at San Jose State University.

The results of changes in body weight, body composition, RMR, total energy intake, and macronutrient composition in the diet are shown in Table 2. Both males and females in the study showed a statistically significant weight gain by the end of the study period ( $2.8 \mathrm{lbs} ; \mathrm{p}=0.002$ and $2.4 \mathrm{lbs} ; \mathrm{p}=0.001$, respectively). Baseline mean body weight in males increased from $165.9 \pm 7.2 \mathrm{lbs}$ to $168.7 \pm 7.3$ by week 16 , while mean body weight for females increased from $129.2 \pm 3.1 \mathrm{lbs}$ to $131.6 \pm 3.2 \mathrm{lbs}$ by week 16 . Individual changes in body weight over the 16 weeks are shown in Figure 1. The reference lines on the figure represent the weight maintenance, and it is clear that the reference line is shifted far to the left indicating that the vast majority of students gained weight over the 16 weeks. More specifically, 44 (70\%) of the participants gained weight 
with $24(38 \%)$ of the individuals gaining 5 or more lbs during the 16 -week study period, while $16(25 \%)$ of the participants lost weight and weights remained unchanged in only 3 individuals.

Five of the 63 individuals changed weight categories during the 16-week study; one decreased weight and moved from normal weight to underweight, while four normal weight individual moved into the overweight category and one of the obese students lost weight and moved to the overweight category. There was no significant relationship between changes in body weight and individual's initial weights $(r=0.15 ; \mathrm{p}=0.25)$.

There were significant changes in body composition in females, but not in males. Percent fat mass in females increased from $29.4 \pm 1.1 \%$ at baseline to $31.5 \pm 1.0 \%(\mathrm{p}=$ 0.002 ) by the end of the study, while percent lean body mass decreased proportionately from $70.8 \pm 1.1 \%$ to $68.6 \pm 1.0 \%(\mathrm{p}=0.001)$. There were no significant changes in $\mathrm{RMR}$ for males $(1780 \pm 83.5 \mathrm{kcal}$ vs. $1801 \pm 89.8 ; \mathrm{p}=0.627)$ or females $(1450 \pm 31.9 \mathrm{kcal} \mathrm{vs}$ $1463 \pm 36.9 \mathrm{kcal} ; \mathrm{p}=0.569)$. No significant changes in total energy intake were reported by either males or females in the study ( $+61 \mathrm{kcal} ; \mathrm{p}=0.680$ and $-40 \mathrm{kcal} ; \mathrm{p}=0.866$, respectively). Males reported an increase in their mean total energy intake from $2100 \pm$ $114 \mathrm{kcal}$ at baseline to $2161 \pm 220 \mathrm{kcal}$ by the end of the study, while females slightly decreased their mean total energy intake from $1840 \pm 98 \mathrm{kcal}$ at baseline to $1800 \pm 75$ kcal by the end of the study. There were no significant differences in intakes of fat, protein, or carbohydrate between baseline and the end of the study in either males or females. 
Table 3 presents the correlation coefficients between changes in body weight, body composition, RMR and total energy intake of college freshmen participants during the 16-week study period. There was a significant association between changes in body weight and change in $R M R(r=0.472 ; p=0.001)$ and, change in percent fat mass $(r=$ $0.297 ; \mathrm{p}=0.019) . \quad$ Exercise practices among the 36 participants who completed exercise surveys are presented in Table 4. Males and females in this study population were very similar in their physical activity levels. Seven (37\%) males and $8(47 \%)$ females met or exceeded the American College of Sports Medicine (ACSM) minimum exercise guidelines for healthy adults over the entire semester. Five (26\%) males and 10 (59\%) females played a sport in high school. Twelve (63\%) males and $12(71 \%)$ females performed a minimum of 1 day of exercise throughout the entire semester. Of the individuals who exercised, $1(8 \%)$ male and 0 females performed resistance training only, $4(33 \%)$ males and $4(33 \%)$ females performed aerobic exercise only, and $7(58 \%)$ males and $8(67 \%)$ females performed both resistance and aerobic exercise. Ten (83\%) males and $11(92 \%)$ females exercised at an intensity of "5" or greater.

Table 5 presents changes in body weight, percent fat mass, and RMR between those that followed the minimum ACSM exercise guidelines vs. those who did not. There were marginally significant differences in changes in body weight $(p=0.09)$; however, no significant differences between RMR $(p=0.40)$ or percent fat mass $(p=0.34)$ were observed. Individuals who did not meet the ACSM minimum guidelines for exercise gained an average of $3.1 \pm 0.9 \mathrm{lbs}$, whereas individuals who met ACSM exercise 
guidelines only gained a mean of $0.8 \pm 1.1 \mathrm{lbs}$. There was a strong negative association between exercise intensity and changes in body weight $(r=-0.851 ; p=0.001)$.

Table 6 presents data on changes in body weight of the 29 individuals in whom data was obtained at 1-year follow-up. Although statistically significant changes in body weight and BMI were observed in these individuals at the end of the 16-week study $(+2.0$ $\pm 4.2 \mathrm{lbs} ; \mathrm{p}=0.014)$, there were no significant differences at the end of 1 year $(+0.8 \pm 4.2$ $l b s ; p=0.269$ ). Figure 2 illustrates the individual differences in body weight of the 29 individuals that completed the 1-year follow-up, at the end of 16 weeks (a), between the end of 16-weeks and 1 year (b), and at the end of 1 year (c). The data are stratified in ascending order as a function of weight gain. Again, the reference lines indicate weight maintenance. It is clear from this illustration that the vast majority of individuals gained weight during the first 16 weeks of the study. This is consistent with the data of the larger group presented in Figure 1. However, the tendency toward positive weight gain was reversed between 16 weeks and 1 year (panel b), and the weight maintenance reference line has shifted far to the right, and is now located between $76^{\text {th }}$ and $79^{\text {th }}$ percentile. As a result, by the end of 1 year (panel c), the reference line falls between the $48^{\text {th }}$ and $52^{\text {nd }}$ percentile, indicating the number of individuals who gained weight was essentially similar to the number of individuals who lost weight.

\section{DISCUSSION}

The results from the present study clearly support the established belief that individuals gain a significant amount of weight during their first semester of college. However, this weight gain appears to be transient in nature, and by the end of 1 year no 
significant differences in weight remained. Furthermore, it is clear from the Figure 1 that weight gain is extremely variable and that some students gain a substantial amount of weight during the first semester in college. Seventy percent of the participants in the present study gained weight and the average weight gain among males and females was $2.5 \pm 0.5 \mathrm{lbs}$, with $38 \%$ of the individuals gaining 5 or more lbs over the 16-week study period. The weight gain observed in the present study is similar to previous studies, which reported a range in freshman weight gain of between 3-7 lbs $(4,5,6)$.

The present study also indicated that changes in body composition accompanied the weight gain in females, but not in males. Females showed increases in \% body fat of $2.1 \%$ over the 16 -week study period, which suggests that weight gained in females was predominantly in fat mass. There is currently little data on the nature of how weight is gained in freshmen students. The only study that previously reported changes in body composition used skin-fold calipers; however, the sites measured and methods used were not specified (4). Because the methods used in this study were incomplete, the data is difficult to interpret. Thus, the present study provides important new information on the nature of weight gain in these individuals during the initial 16 weeks of college life.

There were no significant changes in mean RMR for either males or females, although RMR was moderately associated with changes in weight $(\mathrm{r}=0.47 ; \mathrm{p}=0.001)$. The insignificant changes in RMR may have been due to the small changes observed in lean body mass, which is the best predictor for $\operatorname{RMR}(9,10,11)$.

The present study investigated how diet and exercise practices affected body weight in freshmen students. Although no significant differences in energy intake were 
observed, males reported a slight mean increase in $\mathrm{kcal}(+61.2 \mathrm{kcal})$ and females moderately decreased mean $\mathrm{kcal}(-40.4 \mathrm{kcal})$. Macronutrient distribution was not significantly different throughout the study. Neither energy intake or macronutrient distribution was associated with changes in body weight. Although this data is important, it is critical to remember that dietary intakes were self-reported and therefore are only semi-quantitative in nature. In addition, diet analysis of specific foods may vary in nutrient and energy content between brands. However, if we ignore these potential inaccuracies, the small daily increase in energy reported by men only accounts for approximately 2 pounds of the 2.9 pounds gained. The difference between energy intake and energy output is responsible for changes in body weight; therefore, a decrease in energy output may partially explain the changes in body weight in this population. Meeting or exceeding the minimum ACSM exercise recommendation for healthy adults was used as a tool to categorize (individuals who met or exceeded ACSM recommendations vs. individuals who did not) activity levels of these freshmen. Males and females practiced similar exercise patterns. Actual weight change was poorly associated with exercise practices. Although the differences were only marginally significant $(p=0.09)$ using a two-tailed test, the recommendation of ACSM for exercise in regard to body weight is directed toward the prevention of weight gain and general fitness. Thus, a more appropriate test of the recommendation would be one-tailed in nature. In this regard, the present study provides evidence which suggests that individuals who followed the ACSM recommendations of a minimum of 20 minutes of moderate to vigorous exercise at least 3 days per week were protected from weight gain 
relative to those individuals who did not meet ACSM guidelines. Individuals who met or exceeded ACSM minimum guidelines gained less weight than those who did not $(0.8 \pm$ $1.1 \mathrm{lbs}$ vs. $3.1 \pm 0.9 \mathrm{lbs}$, respectively). Although the differences were only marginally significant $(\mathrm{p}=0.09)$ on a two-tail test, they indicate that meeting or exceeding the ACSM recommendations were protective against weight gain $(p=0.045)$. This is supported by the evidence presented in the present study, which indicates a strong negative association $(\mathrm{r}=-0.851 ; \mathrm{p}=0.03)$ between exercise intensity and changes in body weight. Thus individuals who train at harder intensities may gain less weight during their first semester at college.

Twenty-nine of the 63 individuals were followed for an entire academic year (34 weeks or 9 months total) to investigate whether or not weight gain continued throughout the remainder of the first year of college, was maintained or reverted back to baseline. An unexpected outcome of the present study was the observation that the weight gain observed during the first semester was transient in nature, and by the end of one year no significant differences in weight remained. One of the limitations of the literature on freshmen weight gain is that the studies have been conducted over relatively short periods of time (generally one semester). Thus, the information provided by the present study suggesting that weight gain in freshmen may be transient in nature, represents new and important information. A previous study on the notion of "holiday weight gain," (17) demonstrated very similar findings. The mean weight gain reported in that study was between 0.4 to $0.6 \mathrm{~kg}$ ( 0.88 to $1.3 \mathrm{lbs})$ over a one-year period. 


\section{CONCLUSIONS}

The present study demonstrates that a clinically significant amount of weight is gained in the first semester of college and that this weight gain is variable. The data in this study also demonstrates that weight gain in some individuals can be substantial. In addition, the findings in this study suggest that a small amount of exercise may be protective against weight gain in this population. More research using a larger sample size is needed for a better understanding of long-term weight gain in this population. Instilling good nutrition and fitness habits at a time when lifelong habits are being formed could prove to be a powerful method of improving the health of college populations and discouraging this initial college weight gain. Further research should include pilot studies on developing a college level course, which teaches basic nutrition, metabolism, and exercise programming. 


\section{ACKNOWLEDGEMENTS}

This research was supported by a Zellmer Scholarship Trust Fund Grant from the California Dietetic Association, a Small Research Grant Award from the College Applied Sciences and Arts at San Jose State University, and a Research Assistance Award through the Circle of Friends in the Department of Nutrition and Food Science at San Jose State University. The authors are especially grateful to all of the participants who volunteered their time for this study. The authors would also like to acknowledge the laboratory assistance and data collection performed by Vida Goudarzi, MS, Parinaz Mohamadi, MS, and Begoña Cirera. 


\section{REFERENCES}

1. Center for Disease Control and Prevention, Atlanta. Prevalence of overweight and obesity among adults: United States, 1999 - 2002. National Center for Health Statistics. Retrieved July 22, 2004, from http://www.cdc.gov/nchs/products/pubs/pubd/hestats/obese /obse99.htm

2. Jeffery, R., Drewnowski, A., Epstein, L., Stunkard, A., Wilson, T., Wing, R., Hill, D. Long-term maintenance of weight loss: Current status. Health Psychology 2000;19:5-16.

3. Rosenbaum, M., Leibel, R., Hirsch, J. Obesity. N Engl J Med 1997;337:396-407.

4. Graham, M.A. \& Jones, A.L. Freshman 15: Valid theory or harmful myth? J Am Coll Nutr 2002;50:171-173.

5. Hodge, C., Jackson, L., \& Sullivan, L. The "Freshman 15": Facts and fantasies about weight gain in college women. Psychology of Women Quarterly 1993;17:119125.

6. Hojhosseini, L., Holmes, McProud, L. \& Hollenbeck, C. Changes in body weight, body composition, and resting metabolic rate of college freshmen at a large ethnically diverse university. J Am Coll Nutr In Press.

7. Nieman, D., Trone, G., \& Austin, M. A new handheld device for measuring resting metabolic rate and oxygen consumption. Journal of the American Dietetic Association 2003;103:588-593.

8. American College of Sports Medicine. Guidelines for healthy aerobic activity. Retrieved on August 1, 2004, from: http://acsm.org/health\%2Bfitness/index.htm 
9. Mifflin, M., St. Jeor, S., Hill, L., Scott, B., Daugherty, S., O'Koh, Y. A new predictive equation for resting energy expenditure in healthy individuals. Am J Clin Nutri 1990;51:241-247.

10. Foster, G., Wadden, T., Mullen, J., Stunkard, A., Wang, J., Feurer, I., Pierson, R., Yang, M., Presta, E., Van Itallie, T., Lemberg, P., Gold, J. Resting energy expenditure, body composition, and excess weight in the obese. Metabolism $1988 ; 37: 467-472$.

11. Owen, O., Holup, J., D’Alessio, D., Craig, E., Polansky, M., Smalley, K., et al. A reappraisal of caloric requirements of men. Am J Clin Nutri 1987;46, 875-885.

12. McTigue, K., Garrett, J., Popkin, B. The natural history of the development of obesity in a cohort of young U.S. adults between 1981 and 1998. Ann Intern Med 2002;136:857-864.

13. Allison, D., Fontaine, K., Manson, J., Stevens, J., \& VanItallie, T. Annual deaths attributed to obesity in the United States. JAMA 1999;282:1530-1538.

14. U.S. Department of Health and Human Services. A report of the Surgeon General: Physical activity and health. Retrieved August 5, 2004, from http://www.surgeongeneral.gov/topics/obesity/calltoaction/fact_glance.htm

15. Stein, C., Colditz, G. The epidemic of obesity. J Clin Endocrinol Metab 2004;89:2522-2525.

16. Bray, G. (2004). Medical consequences of obesity. J Clin Endocrinol Metab 2004;89:2583-2589. 
17. Yanovski, J., Yanovski, S., Sovik, K., Nguyen, T., O’Neil, P., \& Sebring, N. (2000). A prospective study of holiday weight gain. N Engl J Med 2000;342:861-867. 
Table 1: Clinical Characteristics of the 63 Study Subjects Studied for 16 Weeks and the Sub-Group of 29 Followed for 1 Year

\begin{tabular}{|l|c|c|}
\hline & $\mathrm{N}=63$ & $\mathrm{~N}=29$ \\
\hline Age (years) & $18 \pm 0.1$ & $18 \pm 0.1$ \\
\hline Gender (M/F) & Male 23 / Female 40 & Male 13 / Female 16 \\
\hline Weight (lbs.) & Male 165.9 \pm 34.3 & Male 157.8 \pm 24.1 \\
& Female $129.2 \pm 19.5$ & Female 130.2 \pm 20.9 \\
\hline Body Mass Index (BMI) $\left(\mathrm{kg} / \mathrm{m}^{2}\right)$ & Male $24.6 \pm 4.3$ & Male 23.3 \pm 2.5 \\
& Female $22.5 \pm 2.8$ & Female 22.6 \pm 2.7 \\
\hline Underweight (BMI $\left.<18.5 \mathrm{~kg} / \mathrm{m}^{2}\right)$ & $0 \mathrm{M} / 1 \mathrm{~F}$ & $0 \mathrm{M} / 0 \mathrm{~F}$ \\
Normal Weight $\left(\mathrm{BMI} 18.5-24.9 \mathrm{~kg} / \mathrm{m}^{2}\right)$ & $16 \mathrm{M} / 32 \mathrm{~F}$ & $11 \mathrm{M} / 15 \mathrm{~F}$ \\
Overweight (BMI $\left.25.0-29.9 \mathrm{~kg} / \mathrm{m}^{2}\right)$ & $3 \mathrm{M} / 5 \mathrm{~F}$ & $2 \mathrm{M} / 0 \mathrm{~F}$ \\
Obese (BMI $\left.>30.0 \mathrm{~kg} / \mathrm{m}^{2}\right)$ & $4 \mathrm{M} / 2 \mathrm{~F}$ & $0 \mathrm{M} / 1 \mathrm{~F}$ \\
\hline
\end{tabular}


Table 2: Changes in Body Weight, Body Composition, RMR, Total Energy Intake, and Macronutrient Composition in Diet in 63* College Freshmen**

\begin{tabular}{|c|c|c|c|c|c|}
\hline & Gender & Week 1 & Weeks 7-8 & Weeks $15-16$ & $\mathrm{P}$ value \\
\hline Weight (lb) & $\begin{array}{l}\mathrm{M} \\
\mathrm{F}\end{array}$ & $\begin{array}{l}165.9 \pm 7.15 \\
129.2 \pm 3.08\end{array}$ & $\begin{array}{l}170.2 \pm 0.51 \\
129.4 \pm 3.24\end{array}$ & $\begin{array}{l}168.7 \pm 7.34 \\
131.6 \pm 3.21\end{array}$ & $\begin{array}{l}0.002 \\
0.001\end{array}$ \\
\hline Fat Mass (\%) & $\begin{array}{l}\mathrm{M} \\
\mathrm{F}\end{array}$ & $\begin{array}{l}20.8 \pm 1.27 \\
29.4 \pm 1.12\end{array}$ & $\begin{array}{l}20.8 \pm 1.17 \\
29.7 \pm 0.98\end{array}$ & $\begin{array}{l}20.5 \pm 1.42 \\
31.5 \pm 1.02\end{array}$ & $\begin{array}{l}0.825 \\
0.002\end{array}$ \\
\hline $\begin{array}{l}\text { Lean Mass } \\
(\%)\end{array}$ & $\begin{array}{l}\mathrm{M} \\
\mathrm{F}\end{array}$ & $\begin{array}{l}79.2 \pm 1.27 \\
70.83 \pm 1.12\end{array}$ & $\begin{array}{l}79.1 \pm 1.17 \\
70.3 \pm 0.98\end{array}$ & $\begin{array}{l}79.5 \pm 1.42 \\
68.6 \pm 1.02\end{array}$ & $\begin{array}{l}0.825 \\
0.001\end{array}$ \\
\hline RMR (kcal) & $\begin{array}{l}\mathrm{M} \\
\mathrm{F}\end{array}$ & $\begin{array}{l}1780.0 \pm 83.46 \\
1449.9 \pm 31.87\end{array}$ & - & $\begin{array}{l}1800.5 \pm 89.76 \\
1462.8 \pm 36.93\end{array}$ & $\begin{array}{l}0.627 \\
0.580\end{array}$ \\
\hline $\begin{array}{l}\text { Total Energy } \\
\text { Intake (kcal) }\end{array}$ & $\begin{array}{l}\mathrm{M} \\
\mathrm{F}\end{array}$ & $\begin{array}{l}2100.4 \pm 114.37 \\
1840.7 \pm 98.16\end{array}$ & & $\begin{array}{l}2161.6 \pm 220.38 \\
1800.3 \pm 74.80\end{array}$ & $\begin{array}{l}0.680 \\
0.763\end{array}$ \\
\hline Fat $(\mathrm{g})$ & $\begin{array}{l}\mathrm{M} \\
\mathrm{F}\end{array}$ & $\begin{array}{l}338.1 \pm 70.60 \\
195.9 \pm 44.43\end{array}$ & - & $\begin{array}{l}187.0 \pm 48.55 \\
135.5 \pm 31.25\end{array}$ & $\begin{array}{l}0.179 \\
0.444\end{array}$ \\
\hline Protein $(\mathrm{g})$ & $\begin{array}{l}\mathrm{M} \\
\mathrm{F}\end{array}$ & $\begin{array}{l}84.7 \pm 5.02 \\
76.1 \pm 6.02\end{array}$ & - & $\begin{array}{l}93.9 \pm 10.35 \\
70.1 \pm 3.49\end{array}$ & $\begin{array}{l}0.474 \\
0.512\end{array}$ \\
\hline Carbohydrate (g) & $\begin{array}{l}\mathrm{M} \\
\mathrm{F}\end{array}$ & $\begin{array}{l}256.1 \pm 18.54 \\
219.8 \pm 13.26\end{array}$ & 工 & $\begin{array}{l}273.3 \pm 26.82 \\
241.4 \pm 12.39\end{array}$ & $\begin{array}{l}0.356 \\
0.162\end{array}$ \\
\hline
\end{tabular}

- Male $=23 ;$ female $=40$

- ** Mean \pm SD 
Table 3: Correlation Coefficients between Changes in Body Weight, Body Composition, RMR and Total Energy Intake of College Freshmen Participants During the 16-Week Study Period

\begin{tabular}{|l|c|c|}
\hline & $\begin{array}{c}\text { Correlation } \\
\text { Coefficient (r) }\end{array}$ & P-value \\
\hline Body Weight vs. RMR & 0.472 & 0.001 \\
\hline Body Weight vs. Fat Mass & 0.297 & 0.019 \\
\hline RMR vs. Fat Mass & 0.119 & 0.355 \\
\hline LM vs. RMR & 0.104 & 0.422 \\
\hline Total Energy Intake vs. Body & 0.203 & 0.126 \\
\hline Weight & & 0.481 \\
\hline Total Energy Intake vs. RMR & 0.094 & 0.423 \\
\hline Total Energy Intake vs. Fat Mass & 0.108 & \\
\hline
\end{tabular}


Table 4: Exercise Patterns Among 36 First Semester Freshmen Students

\begin{tabular}{|c|c|c|}
\hline & Frequency & Percent (\%) \\
\hline $\begin{array}{l}\text { Met or exceeded ACSM } \\
\text { minimum guidelines entire } \\
\text { semester } \dagger\end{array}$ & $\begin{array}{l}\text { Males } 7 \\
\text { Females } 8\end{array}$ & $\begin{array}{l}\text { Males } 36.8 \\
\text { Females } 47.1\end{array}$ \\
\hline $\begin{array}{l}\text { Played a sport in high } \\
\text { school }\end{array}$ & $\begin{array}{l}\text { Males 5 } \\
\text { Females } 10\end{array}$ & $\begin{array}{l}\text { Males } 26.3 \\
\text { Females } 58.8\end{array}$ \\
\hline $\begin{array}{l}\text { Performed at least } 1 \text { day of } \\
\text { exercise }\end{array}$ & $\begin{array}{l}\text { Males } 12 \\
\text { Females } 12\end{array}$ & $\begin{array}{l}\text { Males } 63.2 \\
\text { Females } 70.6\end{array}$ \\
\hline $\begin{array}{l}\text { Performed resistance } \\
\text { training only }\end{array}$ & $\begin{array}{l}\text { Males } 1 \\
\text { Females } 0\end{array}$ & $\begin{array}{l}\text { Males 8.3 } \\
\text { Females } 0\end{array}$ \\
\hline $\begin{array}{l}\text { Performed aerobic exercise } \\
\text { only }\end{array}$ & $\begin{array}{l}\text { Males } 4 \\
\text { Females } 4\end{array}$ & $\begin{array}{l}\text { Males } 33.3 \\
\text { Females } 33.3\end{array}$ \\
\hline $\begin{array}{l}\text { Performed resistance and } \\
\text { aerobic exercise }\end{array}$ & $\begin{array}{l}\text { Males } 7 \\
\text { Females } 8\end{array}$ & $\begin{array}{l}\text { Males 58.3 } \\
\text { Females } 66.7\end{array}$ \\
\hline $\begin{array}{l}\text { Exercise intensity } 5 \text { or } \\
\text { greater }\end{array}$ & $\begin{array}{l}\text { Males } 10 \\
\text { Females } 11\end{array}$ & $\begin{array}{l}\text { Males } 83.3 \\
\text { Females } 91.7\end{array}$ \\
\hline
\end{tabular}

$\uparrow$ ACSM recommends that healthy adults should perform aerobic exercise 3 to 5 days a week at $40 \%$ or $50 \%$ to $85 \%$ of their maximum oxygen uptake reserve (moderate to vigorous physical activity, respectively) for 20 to 60 minutes (ACSM, 2004).

\$Descriptions of intensities are as follows: $5=$ I'm slightly uncomfortable, but can still talk easily; 6 = I can still talk, but am slightly breathless; $7=$ Talking is difficult, I can't finish a sentence without taking a breath; $8=\mathrm{I}$ can utter a response to your question, and I can only keep this pace for a short time period; $9=$ I feel nauseous and I can hardly breath; $10=$ If I keep this pace one more second I will black out. 
Table 5: Changes in Weight, Fat Mass, Lean Mass, and RMR in College Freshmen Who Followed the American College of Sports Medicine (ACSM) Recommendations for Exercise and Those Who Did Not

\begin{tabular}{|l|c|c|c|}
\hline & $\begin{array}{c}\text { Exercised <3 } \\
\text { Days/Wk for 20+ } \\
\text { Minutes/Workout }\end{array}$ & $\begin{array}{c}\text { Exercised } \geq 3 \\
\text { Days/Wk for 20+ }\end{array}$ & \\
\hline Minutes/Workout & \\
\hline Weight (lbs) & $3.1 \pm 0.855$ & $0.79 \pm 1.05$ & 0.094 \\
\hline Change in Fat & $0.47 \pm 0.82$ & $1.06 \pm 1.17$ & 0.341 \\
Mass (\%) & & & \\
\hline Change in & $13.8 \pm 220.7$ & $-1.6 \pm 136.5$ & 0.399 \\
RMR (kcals) & & & \\
\hline
\end{tabular}


Table 6: Changes in Body Weight in 29 Freshmen Students a 16 Weeks, and at 1 Year Follow-up

\begin{tabular}{|l|l|l|l|l|l|}
\hline & Baseline & 16 weeks & P value* & 1 year & P value** \\
\hline Weight $(\mathrm{lbs})$ & $142.6 \pm 26.0$ & $144.6 \pm 27.3$ & 0.014 & $143.4 \pm 27.6$ & 0.269 \\
\hline BMI $\left(\mathrm{kg} / \mathrm{m}^{2}\right)$ & $22.5 \pm 2.7$ & $22.9 \pm 2.9$ & 0.017 & $22.7 \pm 3.0$ & 0.307 \\
\hline
\end{tabular}

$*$ = comparison between baseline and 16-weeks

** = comparison between baseline and 1 year 
Figure 1. Individual Changes in Body Weight in 63 First Semester Freshmen

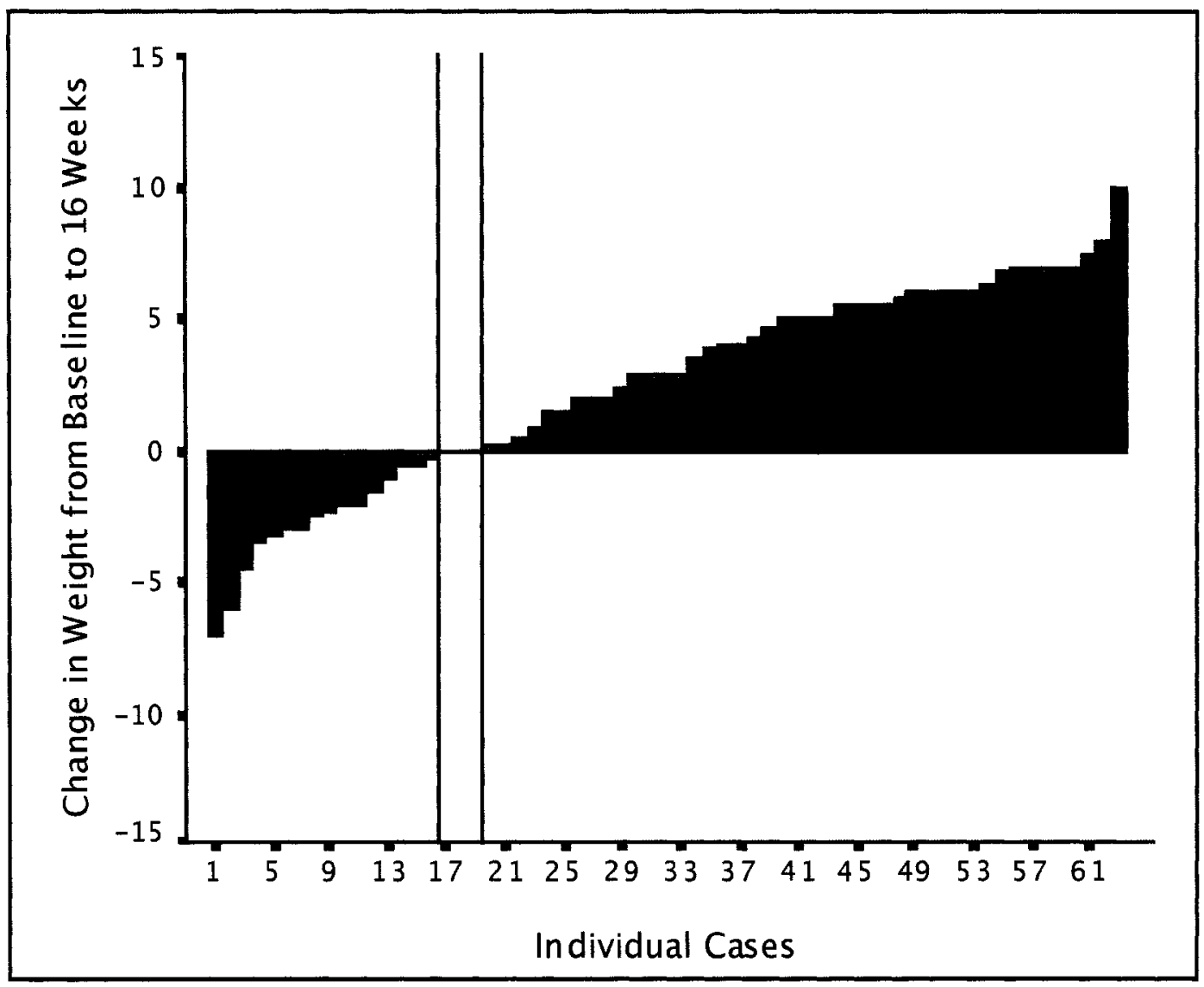


Figure 2. Changes in Body Weight in 29 Freshmen Students at 16 Weeks (a), between 16 Weeks and 1 Year (b), and at the End of 1 Year (c)

a.

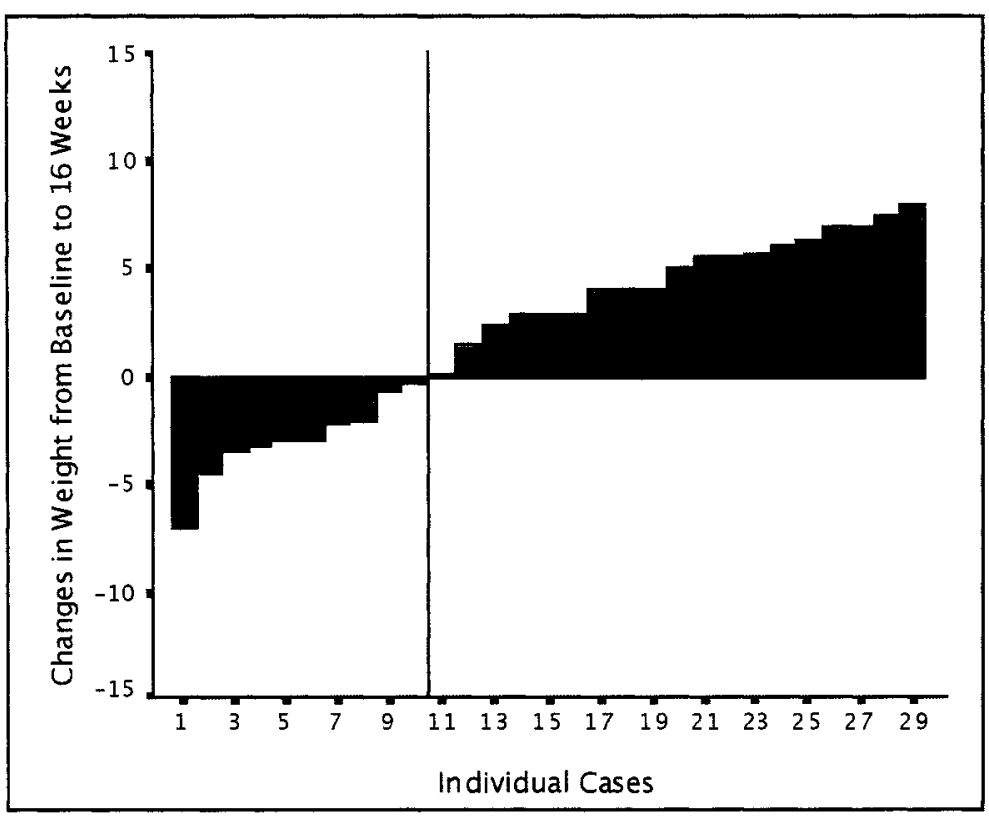

b.

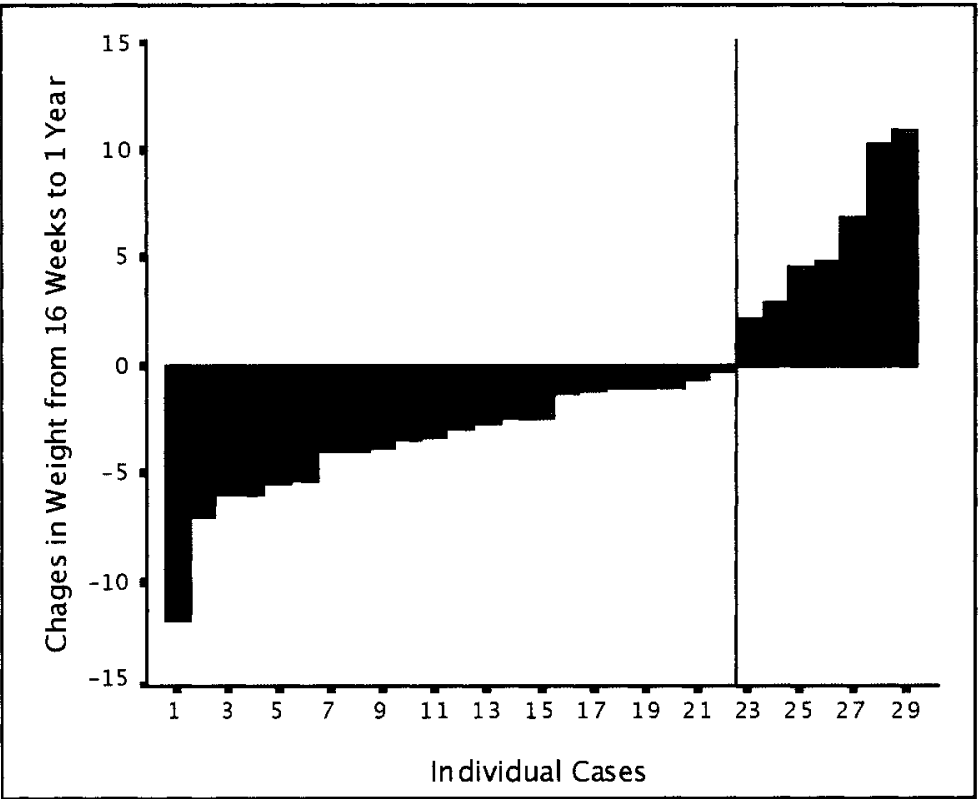


Figure 2. Changes in Body Weight in 29 Freshmen Students at 16 Weeks (a), between 16 Weeks and 1 Year (b), and at the End of 1 Year (c)

c.

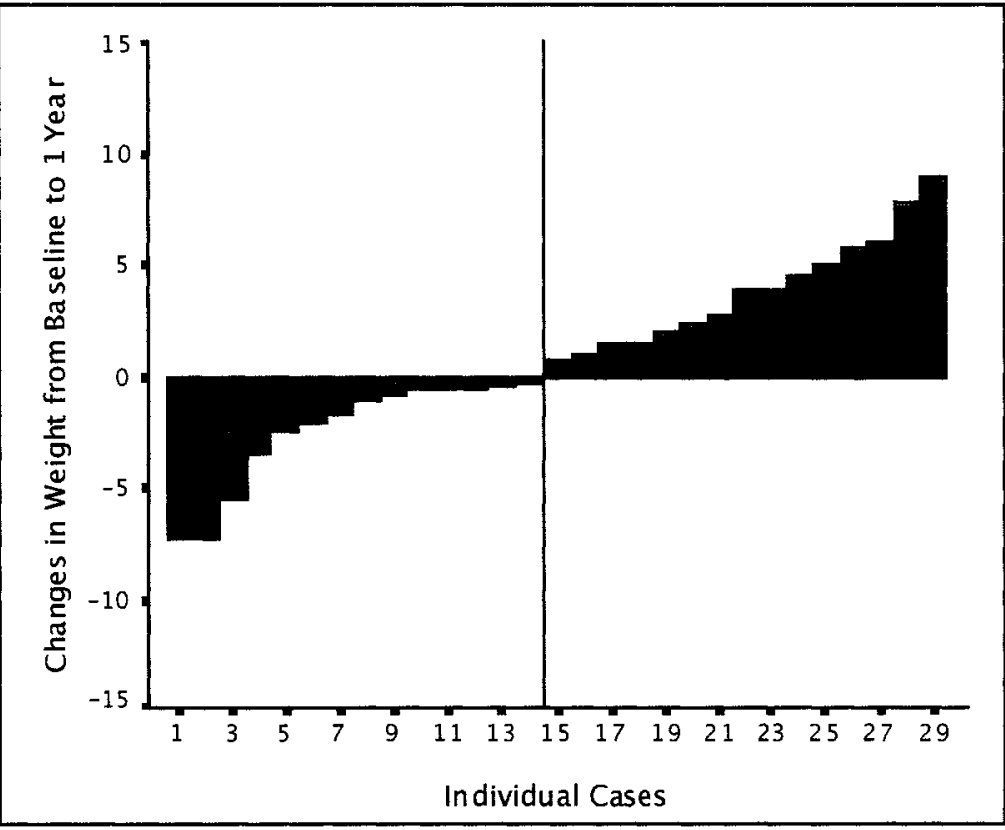


CHAPTER 3

\section{SUMMARY AND RECOMMENDATIONS}

\section{REFERENCES}




\section{Summary and Recommendations}

National data on weight gain in the United States indicate that weight loss programs are ineffective; therefore, targeting when weight is gained is imperative to maintaining a healthy weight. Previous studies have demonstrated an average weight gain of 3-7 lbs. during the first year of college. Data from this study support the established belief that individuals gain a clinically significant amount of weight during their first semester of college. The average weight gain in the present study was $2.5 \pm 0.5$ lbs. Weight gain was highly variable between individuals and was substantial in some participants. Seventy-five percent of the individuals gained weight and $38 \%$ of the participants gained 5 or more lbs. Baseline weights did not appear to have any impact on the amount of weight that was gained. Although the participants in this study gained a clinically significant amount of weight during their first semester, as a group, this weight gain appeared to be transient in nature, and was no longer significant after one year. Of importance, approximately half of the participants maintained their weight gain after one year, supporting the belief that freshmen students are at risk for weight gain.

The nature of how weight is gained was also studied in this population. The data showed that females gained their weight in predominantly fat mass while males gained equally in fat and lean tissue. This new information suggests that females may be at a greater risk for weight related diseases than men in this population.

The present study observed how energy balance affected weight gain. There were no significant differences in energy or macronutrient intake among this study population. There were, however, differences in exercise habits between individuals. Evidence from 
this study suggests that a small amount of exercise may be protective against weight gain that commonly occurs during the first semester of college. Data from this study also suggests that the more intense the exercise, the more protective.

In order to lose or maintain weight, it is important to know daily caloric needs. The present study compared five methods of estimating TEE. Although the present study does not allow these methods to be compared with "true" RMR, the results indicate that all five methods provide reasonably similar estimates, with strong significant correlations among the techniques. Moreover, they suggest that $\mathrm{Kg}^{0.75}$, Harris-Benedict, and Mifflin / St. Jeor, which do not require expensive equipment, closely predict RMR estimated by either $\mathrm{O}_{2}$ or BIA. Therefore, $\mathrm{Kg}^{0.75}$, Harris-Benedict and Mifflin / St. Jeor can be more affordable, useful tools for providing caloric recommendations to healthy, young adults. These estimates can then be used to prescribe appropriate caloric recommendations for young healthy persons seeking weight loss or maintenance.

More research using a larger sample size is needed for a better understanding of long-term weight gain in this population. Instilling good nutrition and fitness habits at a time when lifelong habits are being formed could prove to be a powerful method of improving the health of college populations and discouraging this initial college weight gain. Further research should include pilot studies on developing a college level course, which teaches basic nutrition, metabolism, and exercise programming. Metabolic body size, Harris-Benedict and Mifflin/St. Jeor equations, can be utilized in these courses to estimate caloric needs of freshmen students and provide important awareness of energy balance and weight maintenance. 


\section{References}

Allison, D., Fontaine, K., Manson, J., Stevens, J., \& VanItallie, T. (1999). Annual deaths attributed to obesity in the United States. Journal of the American Medical Association, 282(16), 1530-1538.

American College of Sports Medicine (2004). Guidelines for healthy aerobic activity.

Retrieved on August 1, 2004, from: http://acsm.org/health\%2Bfitness/index.htm

Binzen, C., Swan, P., Manore, M. (2001). Postexercise oxygen consumption and substrate use after resistance exercise in women. Medicine \& Science in Sports \& Exercise. Retrieved June 20, 2004, from http://www.acsm-msse.org

Blackburn, G., Wilson, G., Kanders, B., Stein, L., Lavin, P., Adler, J., Brownell, K. (1989). Weight cycling: the experience of human dieters. American Journal of Clinical Nutrition, 49, 1105-1109.

Bray, G. (2004). Medical consequences of obesity. The Journal of Clinical Endocrinology \& Metabolism, 89, 2583-2589.

Brooks, G., Fahey, T., White, T., Baldwin, K. (2000). Exercise physiology: Human bioenergetics and its applications ( $3^{\text {rd }}$ ed.). Mountain View, CA: Mayfield Publishing Company.

Calle, E., Thun, M., Petrelli, J., Rodriguez, C., Heath, C. (1999). Body-mass index and mortality in a prospective cohort of U.S. adults. The New England Journal of Medicine, 341, 1097-1105.

Case, K., Brahler, J., Heiss, C. (1997). Resting energy expenditure in Asian women measured by indirect calorimetry are lower than expenditures calculated from 
prediction equations. Journal of the American Dietetic Association, 97, 12881292.

Center for Disease Control, Atlanta. Factors contributing to obesity. Retrieved July 22, 2004, from http://www.cdc.gov/nccdphp/dnpa/obesity/contributing_factors.htm

Center for Disease Control, Atlanta. Trends of intake of energy and macronutrientsUnited States, 1971-2000. Retrieved July 22, 2004, from http://www.cdc.gov/mmwr/preview/mmwrhtml/mm5304a3.htm

Colditz, G., Willet, W., Rotnitzky, A., \& Manson, J. (1995). Weight gain as a risk factor for clinical diabetes mellitus in women. Annals of Clinical Nutrition, 122, 431436.

Daly, J., Heymsfield, S., Head, A., Harvey, L., Nixon, D., Katzeff, H., Grossman, G. (1985). Human energy requirements: overestimation by widely used prediction equation. The American Journal of Clinical Nutrition (42), 1170-1174.

Davey, R. (2004). The obesity epidemic: Too much food for thought? British Journal of Sports Medicine, 38, 360-363.

Debate, R. (2001). Racial and gender differences in weight status and dietary practices among college students [Electronic Version]. Adolescence, Winter 2001. Retrieved October 9, 2003, from http://www.findarticles.com/cf_0/m2248/144_36/84722703/print.html

Eckel, R. \& Krauss, R. (1998). American Heart Association call to action: Obesity as a major risk factor for coronary heart disease. Circulation, 97, 2099-2100. 
Frankenfield, D., Rowe, W., Smith, S., Cooney, R. (2003). Validation of several established equations for resting metabolic rate in obese and nonobese people. Journal of the American Dietetic Association (103), 1152-1159.

Foster, G., Wadden, T., Mullen, J., Stunkard, A., Wang, J., Feurer, I., Pierson, R., Yang, M., Presta, E., Van Itallie, T., Lemberg, P., Gold, J. (1988). Resting energy expenditure, body composition, and excess weight in the obese. Metabolism, 37, 467-472.

Garrow, JS. (1987). Energy balance in man. Am J Clin Nut, 45, 1114-1119.

Gilliat-Wimberly, M., Manore, M., Woolf, K., Swan, P., Carroll, S. (2001). Effects of habitual physical activity on the resting metabolic rates and body composition of women aged 35-50 years. Journal of the American Dietetic Association, 101, $1181-1188$.

Golay, A., Allaz, A., Morel, Y., Tonnac, N., Tankova, S., Reaven, G. (1996). Similar weight loss with low- or high-carbohydrate diets. The American Journal of Clinical Nutrition, 63, 174-178.

Graham, M.A. \& Jones, A.L. (2002). Freshman 15: Valid theory or harmful myth? Journal of American College Health, 50, 171-173.

Harris, J, Benedict, F. (1919). A biometric study of basal metabolism in man. Publication 279. Washington, DC: Carnegie Institute.

Hodge, C., Jackson, L., \& Sullivan, L. (1993). The "Freshman 15": Facts and fantasies about weight gain in college women. Psychology of Women Quarterly, 17, 119125. 
Hojhosseini, L., Hollenbeck, C., Holmes, \& McProud, L. (2003). Changes in body weight, body composition, and resting metabolic rate of college freshmen at a large ethnically diverse university. Unpublished graduate project, San Jose State University.

Huang, Z., Willett, W., Manson, J., Rosner, B., Stampfer, M., Speizer, F., \& Colditz, G. (1998). Body weight, weight change, and risk for hypertension in women. Annals of Clinical Nutrition, 128, 81-88.

Jeffery, R., Drewnowski, A., Epstein, L., Stunkard, A., Wilson, T., Wing, R., Hill, D. (2000). Long-term maintenance of weight loss: Current status. Health Psychology. 19, 5-16.

Levitsky, D., Halbmaier, C., \& Mrdjenovic, G. (2004). The freshman weight gain: a model for the study of the epidemic of obesity. International Journal of Obesity, 28,1435-1442.

Matvienko, O., Lewis, D.S., \& Schafer, E. (2001). A college nutrition science course as an intervention to prevent weight gain in female college freshmen. Journal of Nutrition Education, 33, 95-101.

Mayo Clinic (2002). The public health problem of increasing prevalence rates of obesity and what should be done about it. Mayo Clinic Proceedings, 77, 109-113.

McTigue, K., Garrett, J., Popkin, B. (2002). The natural history of the development of obesity in a cohort of young U.S. adults between 1981 and 1998. Annals of Internal Medicine, 136, 857-864. 
Melanson, E., Sharp, T., Seagle, H., Donahoo, W., Grunwald, G., Peters, J., Hamilton, J., Hill, J. (2002). Resistance and aerobic exercise have similar effects on 24-h nutrient oxidation. Medicine \& Science in Sports \& Exercise. Retrieved June 20, 2004, from http://www.acsm-msse.org

Mifflin, M., St. Jeor, S., Hill, L., Scott, B., Daugherty, S., O’Koh, Y. (1990). A new predictive equation for resting energy expenditure in healthy individuals. The American Journal of Clinical Nutrition, 51, 241-247.

National Institute of Health, Washington. Behavioral Risk Factor Surveillance System. Retrieved August 1, 2004, from http:/www.cdc.gov/brfss/

Nielson, S., Siega-Riz, A., Popkin, B. (2002). Trends in Energy Intake in U.S. between 1977 and 1996: Similar shifts seen across age groups. Obesity Research, 10, $370-378$.

Nieman, D., Trone, G., \& Austin, M. (2003). A new handheld device for measuring resting metabolic rate and oxygen consumption. Journal of the American Dietetic Association, 103, 588-593.

Owen, O., Holup, J., D’Alessio, D., Craig, E., Polansky, M., Smalley, K., et al. (1987). A reappraisal of caloric requirements of men. The American Journal of Clinical Nutrition, 46, 875-885.

Owen, O., Kavle, E., Owen, R., Polansky, M., Caprio, S., Mozzoli, M., Zebulon, V., Kendrick, Z., Bushman, M., Boden, G. (1986). A reappraisal of the caloric requirements in healthy women. American Journal of Clinical Nutrition (44), 119. 
Pescatello, L., VanHeest, J. (2000). Physical activity mediates a healthier body weight in the presence of obesity. British Journal of Sports Medicine, 34, 86-93.

Putnam, J., Allshouse, J., Kantor, LS. (2002). U.S. per capita food supply trends: More calories, refined carbohydrates, and fats. USDA Economic Research Service. Food Review, 25, 2-15.

Rosenbaum, M., Leibel, R., Hirsch, J. (1997). Obesity. The New England Journal of Medicine, 337, 396-407.

Roust, L., Hammel, K., Jensen, M. (1994). Effects of isoenergetic, low-fat diets on energy metabolism in lean and obese women. The American Journal of Clinical Nutrition, 60, 470-475.

Sax, L. (1997). Health trends among college freshmen. Journal of American College Health, 45, 252-258.

Stein, C., Colditz, G. (2004). The epidemic of obesity. J Clin Endocrinol Metab, 89, $2522-2525$.

U.S. Department of Health and Human Services (1996). A report of the Surgeon General: Physical activity and health. Retrieved August 5, 2004, from http://www.surgeongeneral.gov/topics/obesity/calltoaction/fact_glance.htm

Willet, W., Dietz, W., Colditz, G. (1999). Guidelines for healthy weight. The New England Journal of Medicine, 341, 427-434.

Yanovski, J., Yanovski, S., Sovik, K., Nguyen, T., O’Neil, P., \& Sebring, N., (2000). A prospective study of holiday weight gain. The New England Journal of Medicine, 342, 861-867. 


\section{APPENDIXES}




\section{APPENDIX A}

\section{IRB Approval}

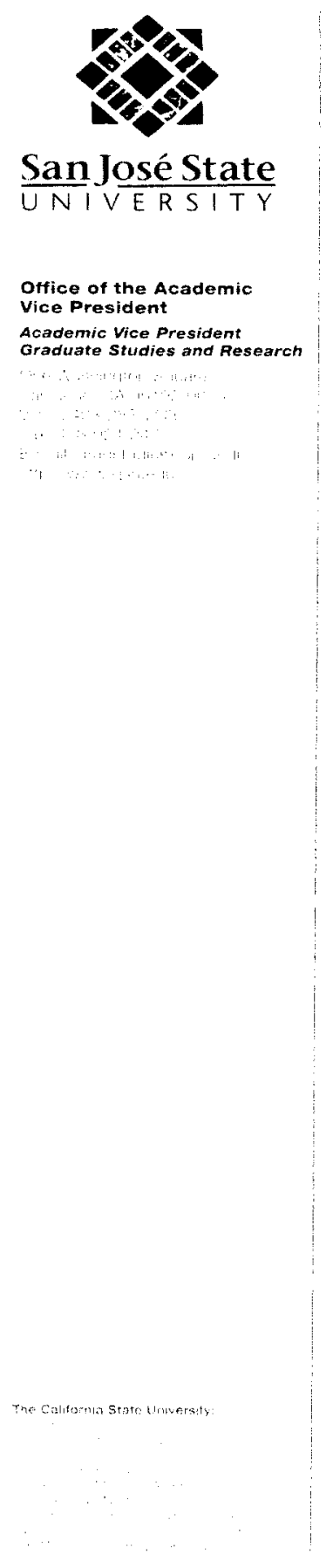

To: Dr. Tawni Holmes

College of Applied Sciences and Arts

Nutrition and Food Science

San José State University

One Washington Square

San José, CA 95192 - 0120

From: Nabil Ibrahim, $\longrightarrow$ AVP, Graduate Studies \& Researeh

Date: June 3, 2003

This letter acknowledges that the Human Subjects-Institutional Review Board has received the request for extension of the following study:

"Nutritional Changes of Incoming Freshman College Students."

Since there are no major changes to the protocol, the Human SubjectsInstitutional Review Board has granted this project a one-year extension effective from the date of this letter. Data collection beyond June 3, 2004 requires an extension request.

If you have any questions, please do not hesitate to contact me at (408) 924-2480 


\section{APPENDIX B}

\section{Consent Form}

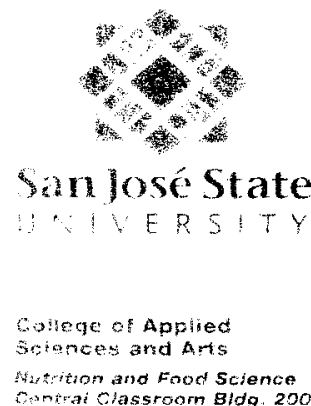

Aintriton and Food Science

\section{Agreement to Participate in Research}

\author{
Responsible Investigators: Clarie Hollenbeck, and Tawni Holmes
}

Title of Protocol: Nutritional Changes of Incoming College Freshman Students

I have been asked to participate in a research study investigating dietary and nutritional changes that occur in incoming college freshman students.

I will be asked to keep 3-day dietary records on three separate days during the Fall semester occasions (beginning, middle and end). In addition, $I$ will be asked to fill out a shortened version of a food frequency questionnaire at the beginning and end of the study period. 1 will also have nutritional measurements made of my resting energy expenditure, body weight and body composition at three times during the semester, corresponding to the three-day dietary records. Resting energy expenditure is a measurement of my energy requirement during rest and is made by measuring the amount of oxygen I used over the course of a few minutes. The measurement is made by having me breath into a mouthpiece attached to a device that measures oxygen. Body composition will be measured by a standard bioelectrical impedance apparatus. This is a computer device that estimates percent body fat and lean body mass (non-fat components of my body). Two electrode patches similar to electro-cardiographic patches will be placed on one of my hands and one of my feet, and the resistance to the flow of a small electrical current (from the computer) between the two patches will provide an estimate of my body composition. Both of these two measurements require only a few minutes of my time (less than 15 minutes).

I understand that the risk involved in participating in this study is very low and would not be greater than the risk encountered in everyday life.

I understand that I will receive no direct benefit from the study. However, my participation will help advance our understanding of dietary changes faced every year by freshman starting college.

I also understand that my personal information obtained from my participation in this study, will be shared with me, but will not be disclosed to any other sources in a manner that would identify me in any manner without my explicit written permission. I also understand that the results of this study may be published but no information will be released in a manner that could identify me or any of the subjects participating in this study.

I understand that $I$ will receive no compensation for participating in this study. 
$I$ understand that if I have any questions about this research that I am expected to ask them of the principle investigators Drs. Hollenbeck, Holmes and Sucher at (408) 924-3100.

Complains about the research may be presented to Dr McProud (Chair, Department of Nutrition and Food Science (408) 924-3100). Questions about research, subjects' rights, or research-related injury may be presented to (Nabil Ibrahim, PH.D.) Associate Vice President for Graduate Studies and Research, at (408) 924-2480.

I understand that my participation in this study is strictly voluntary and that I may refuse to participate in any part of the study or to withdraw from the study at any time without prejudice to myself or my relationship to San Jose State University or any other participating institution; and, that my decision to not participate or to withdraw from the study will not cause me to lose any services to which I would otherwise be entitled.

$I$ understand that the information gathered from this research study will only be valid if $I$ complete the entire program, including all the metabolic measurements made and record by dietary food intake accurately and completely on the three occasions.

I acknowledge that I have received a signed and dated copy of this consent form.

- My signature on this document indicates my agreement to participate in the study.

- The signature of one of the investigators on this document indicates agreement to include the named subject in the research and attestation that the subject has been fully informed o his or her rights

Signature (Participant)

Date

Signature (Investigator)

Date 


\section{APPENDIX C}

\section{Exercise Surveys}

\section{Exercise Questions for Frosh Study, Semester 1, \#1}

1. Did you play sports in high school? If yes, what sport, and did you play your senior year?

$$
\begin{array}{ll}
0 & \text { Yes } \\
1 & \text { No }
\end{array}
$$

2. Did you take a PE class during your last semester (in high school)?

$$
\begin{array}{ll}
0 & \text { Yes } \\
1 & \text { No }
\end{array}
$$

3. Do you work? $0=$ yes; $1=$ no

Is your job:

0 Sedentary (seated most of the day)

1 Moderately active (stand most of the day, e.g.: grocery checker)

2 Active (walking, lifting, squatting throughout the entire day, e.g.: waitress)

3 Very active (Lifting heavy objects all day, e.g.: lumber jack)

4. If you work, how many hours a week do you work?

$$
\begin{array}{ll}
0 & 0 \\
2 & 1-15 \\
3 & 16-30 \\
4 & 31+
\end{array}
$$


5. Did you do any type of exercise over the summer? $0=$ yes; $1=$ no

\section{If yes, what type?}

a. Cardiovascular:

Type of exercise:

Duration:

$$
\begin{array}{ll}
0 & <20 \text { minutes } \\
1 & >20 \text { minutes }
\end{array}
$$

ii. Number of days per weeks:

0
1
2
3
4
5
6
7

iii. Number of weeks exercise was consistently performed:

$$
\begin{array}{ll}
0 & 1-4 \\
1 & 5-8 \\
2 & 9-12
\end{array}
$$

iv. Intensity Level: 1-10_(From exercise intensity scale on last page)

b. Resistance Training:

i. Number of days/week:

0
1
2
3
4
5
7

ii. Number of weeks exercise was consistently performed:

$\begin{array}{ll}0 & \\ 1 & 1-4 \\ 2 & 5-8 \\ 3 & 9-12\end{array}$


iii. Number of sets (total/workout):

$$
\begin{array}{ll}
0 & <8 \\
1 & 8-10 \\
2 & 11+
\end{array}
$$

iv. Number of reps:

$$
\begin{array}{ll}
0 & <8 \\
1 & 8-12 \\
2 & 13+
\end{array}
$$

c. Other (such as an organized sport or yoga): type of exercise:

i. Duration:

$$
\begin{aligned}
& 0<20 \text { minutes } \\
& 1>20 \text { minutes }
\end{aligned}
$$

ii. Number of days/week:

0
1
2
3
4
5
6
7

\section{Do you exercise now?}

$$
0=\text { yes } ; 1=\text { no }
$$

If it is different than the summer or your senior year of high school, in what way(s) is it different?
1 Decrease
2 Same
3 Increase 


\section{What do you do for exercise right now?}

a. Cardiovascular:

Type of exercise:

Duration:

$$
\begin{array}{ll}
0 & <20 \text { minutes } \\
1 & >20 \text { minutes }
\end{array}
$$

ii. Number of days per weeks:

0
1
2
3
4
5
6
7

iii. Number of weeks exercise was consistently performed:

$$
\begin{array}{ll}
0 & 1-4 \\
1 & 5-8 \\
2 & 9-12
\end{array}
$$

iv. Intensity Level: 1-10 (From exercise intensity scale)

b. Resistance Training:

i. Number of days/week:

0
1
2
3
4
5
6
7

ii. Number of weeks exercise was consistently performed:

0

$1 \quad 1-4$

$2 \quad 5-8$

$3 \quad 9-12$ 
iii. Number of sets (total/workout):

$$
\begin{array}{ll}
0 & <8 \\
1 & 8-10 \\
2 & 11+
\end{array}
$$

iv. Number of reps:

$$
\begin{array}{ll}
0 & <8 \\
1 & 8-12 \\
2 & 13+
\end{array}
$$

c. Other (such as an organized sport or yoga): type of exercise:

i. Duration:

$$
\begin{aligned}
& 0<20 \text { minutes } \\
& 1>20 \text { minutes }
\end{aligned}
$$

ii. Number of days/week:

$$
\begin{aligned}
& 0 \\
& 1 \\
& 2 \\
& 3 \\
& 4 \\
& 5 \\
& 6 \\
& 7
\end{aligned}
$$

8. (If you currently exercise) Why do you exercise? (if more than one reason, rank them in order of preference with 1 being your $1^{\text {st }}$ reason and so on.

0 Weight control: yes/no rank

1 Stress management: yes/no rank

2 You enjoy it: yes/no rank

3 You want to build muscle: yes/no rank

4 Other: 


\section{Exercise Intensity Scale}

- Level 1: I'm watching TV

- Level 2: I'm comfortable and could maintain this pace all day long

- Level 3: I'm still comfortable, but am breathing a bit harder

- Level 4: I feel good and can carry on a conversation effortlessly

- Level 5: I'm slightly uncomfortable, but can still talk easily

- Level 6: I can still talk, but am slightly breathless

- Level 7: Talking is difficult, I can't finish a sentence without taking a breath

- Level 8: I can utter a response to your questions and I can only keep this pace for a short time period.

- Level 9: I feel nauseous and I can hardly breathe.

- Level 10: If I keep this pace one more second I will black out

\section{Exercise Questions for Frosh Study, Semester 1 \& 2, \#2}

1. Did you exercise throughout the entire semester? If yes, was it different than the beginning of the year? Did your exercise:

$\begin{array}{ll}1 & \text { Decrease } \\ 2 & \text { Same } \\ 3 & \text { Increase }\end{array}$

2. Average number of days per week exercised:

3. Average number of minutes exercise:

4. Average intensity exercised: (1-10) (from intensity scale on last page)

5. Do you work? $0=$ yes; $1=$ no Is your job:

0 Sedentary (seated most of the day)

1 Moderately active (stand most of the day, e.g.: grocery checker)

2 Active (walking, lifting, squatting throughout the entire day, e.g.: waitress)

3 Very active (Lifting heavy objects all day, e.g.: lumber jack)

6. If you work, how many hours a week do you work?
$\begin{array}{lll}0 & 0\end{array}$
$11-15$
$216-30$
$330+$ 
7. Do you currently exercise? $0=$ yes; $1=$ no

\section{If yes, what type?}

a. Cardiovascular:

Type of exercise:

i. Duration:

$$
\begin{array}{ll}
0 & <20 \text { minutes } \\
1 & >20 \text { minutes }
\end{array}
$$

ii. Number of days per weeks:

0
1
2
3
4
5
6
7

iii. Number of weeks exercise was consistently performed:

$$
\begin{array}{ll}
0 & 1-4 \\
1 & 5-8 \\
2 & 9-12
\end{array}
$$

iv. Intensity Level: 1-10 (From exercise intensity scale)

b. Resistance Training:

i. Number of days/week:

$\begin{array}{ll}0 & 1 \\ 1 & 2 \\ 2 & 3 \\ 3 & 4 \\ 4 & 5 \\ 5 & 6 \\ 6 & 7\end{array}$

ii. Number of weeks exercise was consistently performed:

0

$1 \quad 1-4$

$25-8$

$\begin{array}{ll}3 & 9-12\end{array}$ 
iii. Number of sets (total/workout):

$$
\begin{array}{ll}
0 & <8 \\
1 & 8-10 \\
2 & 11+
\end{array}
$$

iv. Number of reps:

$$
\begin{array}{ll}
0 & <8 \\
1 & 8-12 \\
2 & 13+
\end{array}
$$

b. Other (such as an organized sport or yoga): type of exercise:

i. Duration:

$0<20$ minutes

$1>20$ minutes

ii. Number of days/week:

0
1
2
3
4
5
6

10 (If you currently exercise) Why do you exercise? (if more than one reason, rank them in order of preference with 1 being your $1^{\text {st }}$ reason and so on.

0 Weight control: yes/no rank

1 Stress management: yes/no rank

2 You enjoy it: yes/no rank

3 You want to build muscle: yes/no rank

4 Other: 


\section{Exercise Intensity Scale}

- Level 1: I'm watching TV

- Level 2: I'm comfortable and could maintain this pace all day long

- Level 3: I'm still comfortable, but am breathing a bit harder

- Level 4: I feel good and can carry on a conversation effortlessly

- Level 5: I'm slightly uncomfortable, but can still talk easily

- Level 6: I can still talk, but am slightly breathless

- Level 7: Talking is difficult, I can't finish a sentence without taking a breath

- Level 8: I can utter a response to your questions and I can only keep this pace for a short time period.

- Level 9: I feel nauseous and I can hardly breathe.

- Level 10: If I keep this pace one more second I will black out

\section{Exercise Questions for Frosh Study, Semester 2, \#1}

\section{Do you work? $0=$ yes; $\mathbf{1}=$ no Is your job:}

0 Sedentary (seated most of the day)

1 Moderately active (stand most of the day, e.g.: grocery checker)

2 Active (walking, lifting, squatting throughout the entire day, e.g.: waitress)

3 Very active (Lifting heavy objects all day, e.g.: lumber jack)

\section{If you work, how many hours a week do you work?}

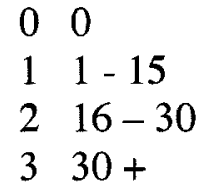

3. Do you currently exercise? $0=$ yes; $1=$ no If yes, what type?

c. Cardiovascular: Type of exercise:

i. Duration

$1=<20$ minutes

$2=>20$ minutes 
ii. Number of days per weeks:

0
1
2
3
4
5
6
7

ii. Number of weeks exercise was consistently performed:
0
$1-4$
5-8
$9-12$

iii. Intensity Level: 1-10 (From exercise intensity scale)

d. Resistance Training:

i. Number of days/week:

0
1
2
3
4
5
6
7

ii. Number of weeks exercise was consistently performed:

0

$1-4$

5-8

9-12

iii. Number of sets (total/workout):

$<8$

$8-10$

$11+$

iv. Number of reps:

$<8$

8-12

$13+$

e. Other (such as an organized sport or yoga): type of exercise:

i. Duration:

$0<20$ minutes

$1>20$ minutes 
ii. Number of days/week:

$$
\begin{aligned}
& 0 \\
& 1 \\
& 2 \\
& 3 \\
& 4 \\
& 5 \\
& 6 \\
& 7
\end{aligned}
$$

4. (If you currently exercise) Why do you exercise? (if more than one reason, rank them in order of preference with 1 being your $1^{\text {st }}$ reason and so on.

0 Weight control: yes/no rank

1 Stress management: yes/no rank

2 You enjoy it: yes/no rank

3 You want to build muscle: yes/no rank

4 Other:

\section{Exercise Intensity Scale}

- Level 1: I'm watching TV

- Level 2: I'm comfortable and could maintain this pace all day long

- Level 3: I'm still comfortable, but am breathing a bit harder

- Level 4: I feel good and can carry on a conversation effortlessly

- Level 5: I'm slightly uncomfortable, but can still talk easily

- Level 6: I can still talk, but am slightly breathless

- Level 7: Talking is difficult, I can't finish a sentence without taking a breath

- Level 8: I can utter a response to your questions and I can only keep this pace for a short time period.

- Level 9: I feel nauseous and I can hardly breathe.

- Level 10: If I keep this pace one more second I will black out 